\section{Check for updates}

Cite this: Mater. Adv., 2021, 2, 2200

Received 25th December 2020 Accepted 15th February 2021

DOI: 10.1039/d0ma01015d

rsc.li/materials-advances

\title{
Magnetic polymer nanomaterials for sample pretreatment in proteomics $\dagger$
}

\author{
Bin Luo, ${ }^{a}$ Lingzhu Yu, ${ }^{a b}$ Jia He, ${ }^{a}$ Zhiyu Li, ${ }^{a}$ Fang Lan (D) *ab and Yao Wu (D *ab
}

Protein post-translational modifications (PTMs) play important roles in the regulation of protein functions and cellular processes, which cannot be easily analyzed due to a large number of obstacles, such as the substoichiometric level of PTM proteins, the diversity and complexity of PTM proteins, and the highintensity interference from ordinary proteins. Therefore, the selective and effective separation of trace amounts of PTM peptides from complex samples is the first crucial step for PTMs. In order to meet the aforesaid requirements, magnetic polymer nanomaterials have emerged as highly effective agents for sample pretreatment in PTM proteomics. In the present review, the recent design of magnetic polymer nanomaterials and their applications in two typical types of protein PTMs (glycosylation and phosphorylation) are summarized. In addition, the development trend of magnetic polymer nanomaterials in PTM proteomics is discussed.

\section{Introduction}

In spite of great advancements in genetics, the complex living systems are still far from complete understanding, and the main reason behind it is that living systems are far more complex than those predicted by nucleotides. In the complex process of transcription to translation, dozens of proteins can be produced at a single gene site through multiple expression controls, such as RNA splicing and selective translation initiation. ${ }^{1,2}$ In addition, some new regulatory mechanisms, such as the regulation of small RNAs, are also involved in complex gene expression processes, producing more unpredictable proteins. ${ }^{3}$ Therefore, as the direct executor of living systems, proteins have attracted great attention in bioscience research. As an important complement to genomics, proteomics is developed to comprehensively explore the biological processes at the level of proteins. Proteomics essentially involves studying the characteristics of proteins on a large scale, including the expression level of proteins, post-translational modifications (PTMs), and protein-protein interactions. ${ }^{4,5}$

In comparison to ordinary proteomics, PTM proteomics provides a better understanding of physiological and pathological processes in organisms. ${ }^{6,7}$ More than 300 different types of protein PTMs, such as glycosylation, acetylation, phosphorylation,

\footnotetext{
${ }^{a}$ National Engineering Research Center for Biomaterials, Sichuan University, Chengdu 610064, P. R. China. E-mail: fanglan@scu.edu.cn, wuyao@scu.edu.cn

${ }^{b}$ College of Biomedical Engineering, Sichuan University, Chengdu 610064, P. R. China

$\dagger$ Electronic supplementary information (ESI) available. See DOI: 10.1039/ d0ma01015d
}

and ubiquitination, have been confirmed till now. ${ }^{8}$ Protein PTMs are closely related to various cellular processes, gene expression regulation, signal transduction pathway regulation, and protein kinases activation. ${ }^{9-11}$ Among them, protein glycosylation and phosphorylation are widely studied because of the close relationship between their abnormalities and diseases. ${ }^{12}$ Vasaikar et al. employed phosphorylated proteomics analysis to prove that RB1 protein hyperphosphorylation was associated with increased proliferation and decreased apoptosis of colon cancer cells, which explained why the tumor suppressor gene RB1 was amplified in colon tumors. ${ }^{13}$ Recently emerging evidence suggests that phosphoprotein stathmin is highly expressed in different types of human tumor tissues, such as breast cancer, oral carcinoma, liver cancer, and lung cancer. ${ }^{14}$ For protein glycosylation, various glycoproteins have been confirmed as cancer biomarkers. For example, glycoprotein carbohydrate antigen 15-3 (CA15-3) is the routine biomarker for the screening and monitoring of breast cancer. ${ }^{15}$ A high level of carbohydrate antigen 12-5 (CA12-5) is required for gastric cancer and ovarian cancer. ${ }^{16}$ The combined detection of CA12-5 and CA15-3 is essential for the diagnosis of primary ovarian cancer. ${ }^{17}$ Recently, the researchers illuminated the role of protein glycosylation in the heterogeneity of serous ovarian cancer (HGSC), showing the close relationship between the N-glycan structure and tumor molecular subtypes. ${ }^{18}$

In recent years, advanced mass spectrometry instruments and technologies have been used to achieve fast, accurate, sensitive, and high-throughput protein detection, providing a solid foundation for proteomics research. ${ }^{19,20}$ However, mass spectrometry-based PTM proteomics still faces various obstacles and challenges. The first obstacle originates from the complexity of protein samples. The charge state, molecular size, hydrophilicity, 
and conformation of proteins cause difficulties in mass detection. In addition, proteins often coexist with other biological macromolecules, such as DNA and fatty acid. ${ }^{21}$ The second obstacle occurs due to the low abundance of PTM proteins and the high abundance of interfering proteins in real biological samples. For example, 22 high-abundance proteins account for $99 \%$ of total serum proteins. $^{22}$ Therefore, it is difficult to efficiently identify target PTM proteins by mass spectrometry. The third obstacle comes from the diversity and complexity of PTM proteins. For example, reversible phosphorylation and multiple phosphorylation sites make the detection difficult. ${ }^{23}$ Various glycan molecules modified on proteins make glycosylation more complicated than protein phosphorylation. Hence, the elimination of interfering substances and the improvement of the purity and relative abundance of PTM proteins are the main prerequisites for MS-based proteomics. In recent years, nanomaterials combined with the solid-phase extraction technique have emerged as a highly effective means for the separation and enrichment of proteins. Due to their high specific surface area and abundant affinity sites, nanomaterials play an important role in proteomics research.

In order to meet the requirements of biological separation, nanomaterials generally include two parts-substrates and functional moieties (Fig. 1). Substrates are responsible for biological separations and act as carriers for functional molecules. Functional moieties are designed to capture targets. Magnetic nanoparticles, especially iron oxides, are widely used for magnetic resonance imaging, sensing, targeted drug delivery, and biological separation. $^{24}$ Due to their low toxicity, fast magnetic response, stable physical and chemical properties, and flexible surface functionalization, magnetic $\mathrm{Fe}_{3} \mathrm{O}_{4}$ nanoparticles are most commonly used in proteomics by introducing different feasible modifications on their surfaces. Polymers are ideal and excellent $\mathrm{Fe}_{3} \mathrm{O}_{4}$ modifiers for bio-separation applications. Polymers possess the following inherent characteristics: (1) high surface area, (2) abundant affinity sites, (3) adjustable flexible and rigid structure, (4) flexible modification, and (5) effective interaction space with target molecules. Therefore, magnetic polymer nanomaterials have emerged as highly effective agents for sample pretreatment in proteomics. ${ }^{25}$ In addition, the magnetic smart polymer nanomaterials provide a series of material platforms by integrating different functional monomers into polymer backbones, and these polymers can serve as stimulus-responsive units or biomolecular recognition units. Through the conformational transformation of polymer chains and the synergistic interactions among functional molecules, guest biomolecules, and polymer backbones, weak biomolecular recognition signals can be captured and recognized. ${ }^{26}$

In the current review, the design and application of magnetic polymer nanomaterials for sample pretreatment in proteomics are analyzed. First, different preparation methods of magnetic polymer nanomaterials are summarized, and their capture performance in ordinary protein separation is discussed. Second, the applications of magnetic polymer nanomaterials in glycoproteomics and phosphoproteomics are enumerated based on their enrichment and separation mechanisms. Finally, the prospects of magnetic polymer nanomaterials in proteomics are delineated.

\section{Preparation methods of magnetic polymer nanomaterials}

Magnetic polymer nanomaterials usually consist of magnetic matrices and polymer moieties, and their preparation strategies

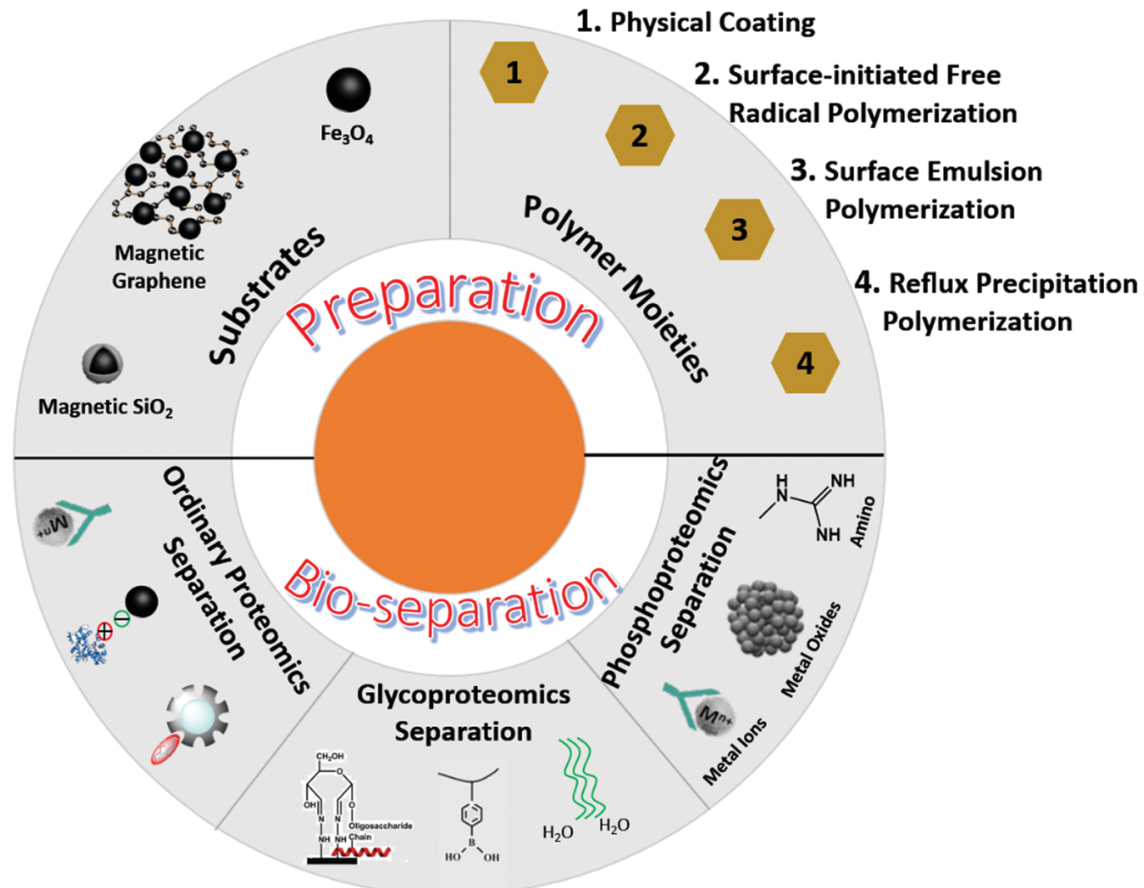

Fig. 1 Schematic illustration of the preparation and bioseparation application of magnetic polymer nanomaterials. 
mainly include (i) physical coating method, (ii) surface-initiated free radical polymerization, (iii) emulsion polymerization, and (iv) reflux precipitation polymerization.

\subsection{Physical coating}

Magnetic nanoparticles and polymers are prepared separately, and then two moieties are combined through electrostatic interactions, hydrogen bonding, van der Waals force, and cross-linkers (Fig. 2). Yang et al. prepared a new type of magnetic polymer nanomaterial based on an improved emulsion cross-linking method. $\mathrm{Fe}_{3} \mathrm{O}_{4}$ nanoparticles and carboxymethyl chitosan (CMCS) were ultrasonically dispersed in water and mixed with paraffin wax. $\mathrm{Fe}_{3} \mathrm{O}_{4} / \mathrm{CMCS}$ composite nanospheres were obtained through the participation of the surfactant and the cross-linking agent (genipin). ${ }^{27}$ Masoudi et al. synthesized $\mathrm{Fe}_{3} \mathrm{O}_{4} / \mathrm{PEG}$ nanoparticles by adding magnetic iron oxide nanoparticles into a polyethylene glycol (PEG) solution under mechanical stirring for 24 hours. ${ }^{28}$ According to application requirements, different polymers, such as polyvinyl alcohol (PVA), polyvinyl pyrrolidone (PVP), and polyacrylic acid (PAA), can be modified on magnetic nanoparticle surfaces by physical coating. However, due to the non-covalent bindings of the coated materials, the prepared magnetic polymer nanomaterials are easily affected by complex application environments, such as $\mathrm{pH}$ and temperature.

\subsection{Surface-initiated free radical polymerization}

Since 1995, atom transfer radical polymerization (ATRP) has become the common method to synthesize polymers with precisely controlled molecular structures. Performing ATRP polymerization on the surface of the substrate is known as surface-initiated ATRP. Recently, the surface-initiated ATRP method has become a popular approach to prepare magnetic polymer nanomaterials. First, the magnetic nanoparticles are modified with an initiator to become macromolecular initiators, and then dispersed in the required monomer solution to initiate the polymerization reaction with suitable catalysts. Based on the principle of monomer polymerization, the magnetic polymer nanomaterials were successfully prepared, which can effectively control the molecular weight of the polymer. Notably, initiators on the surface of magnetic nanoparticles are the most important agents in surface-initiated ATRP. In order to introduce an initiator, surfaces of magnetic nanoparticles are generally coated with CMCS, silicon dioxide $\left(\mathrm{SiO}_{2}\right)$, and polydopamine (PDA). Wu et al. anchored chloroacetic acid (initiator) on $\mathrm{Fe}_{3} \mathrm{O}_{4}$ nanospheres through coordination exchange and then modified polyacrylic acid polymer brushes on the nanospheres using acrylic acid to obtain magnetic polymer nanomaterials. ${ }^{29} \mathrm{Yu}$ et al. reported a new type of $\mathrm{Fe}_{3} \mathrm{O}_{4} @ P D A @ P M A A$ nanosphere. First, magnetic nanoparticles prepared by the solvothermal method were coated

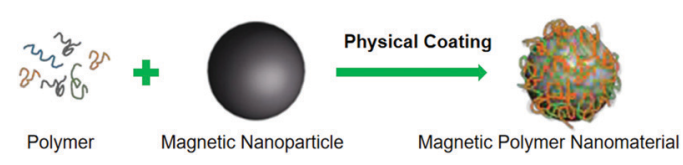

Fig. 2 Schematic illustration of the preparation of magnetic polymer nanomaterials by a physical coating method. with PDA, which provided active sites to introduce the initiator. Through surface-initiated free radical polymerization, nanoparticles were then modified with PMAA brushes. ${ }^{30}$ Luo et al. also exploited a similar material covered with PDA before polymerization. Through the self-polymerization of dopamine, surface-initiated free radical polymerization, and modification after polymerization, $\mathrm{Fe}_{3} \mathrm{O}_{4} / \mathrm{PDA} / \mathrm{PAMA}-\mathrm{Arg}$ nanospheres were finally obtained. ${ }^{31}$ However, the severe anaerobic and water-free conditions of the surfaceinitiated ATRP method have affected its wide range of applications for preparing magnetic polymer nanomaterials.

\subsection{Emulsion polymerization}

Water and oil phases containing monomers and magnetic nanoparticles form emulsion droplets in the presence of surfactants under the shear force. Polymerization reactions proceed in emulsion droplets and generate magnetic polymer nanomaterials. It contains these characteristics: there will be two phases of water and oil in the system to form emulsion droplets; the process requires surfactants and shear force; the polymerization reaction takes place in the emulsion droplets. For example, magnetic nanoparticles prepared by pyrolysis and methyl methacrylate (MMA) were dispersed in $n$-hexane, and sodium dodecylbenzene sulfonate (SDBS) and PVA were dissolved in the aqueous phase. The mixture was sonicated and emulsified to form one small emulsion droplet. The polymerization reaction was initiated by ammonium persulfate (APS) at $80^{\circ} \mathrm{C}$ and continued for five hours. In comparison to the conventional double mini-emulsion polymerization, this method can form uniform magnetic polymer nanospheres with high saturation magnetization. ${ }^{32}$ Lan et al. used Tween- 80 as the surfactant and replaced PVA with triethylene glycol (TEG) to prepare another kind of magnetic polymer nanomaterial. ${ }^{33}$ Notably, the surfactants or stabilizers used in the emulsion polymerization could be difficult to remove, which will affect the subsequent application of the prepared magnetic polymer nanomaterial to a certain extent.

\subsection{Reflux precipitation polymerization}

Unlike emulsion polymerization, reflux precipitation polymerization (RPP) takes advantage of polymers free of any surfactant or stabilizer. In RPP, under a reflux system, monomers and initiators are dissolved in a solvent to form a homogeneous system for polymerization reactions, and subsequently, the asgenerated polymer chains precipitated in the continuous medium. A large amount of monomers is generally used to form polymers in the RPP method. As RPP is an easy, fast, efficient, and stable fabrication process, it is an effective approach to prepare different types of polymer-based composites. RPP is also widely employed to prepare magnetic polymer nanomaterials by combining polymers with magnetic nanoparticles. Jia et al. fabricated a Zn(II)-immobilized polyvinyl imidazole (PVIM) shell-coated magnetic microsphere (dubbed $\mathrm{Fe}_{3} \mathrm{O}_{4} @$ @PVIM@Zn(II)) through RPP and the metal-ion affinity strategy. The core-shell magnetic microsphere had a $20 \mathrm{~nm}$-thick polymer layer and high magnetic responsiveness $\left(32.6 \mathrm{emu} \mathrm{g}^{-1}\right){ }^{34}$ Yang et al. first prepared poly(AA-co-DMA) nanohydrogels by RPP and then modified the surface with $\mathrm{Fe}_{3} \mathrm{O}_{4}$ and DOX to form magnetic DOX- $\mathrm{Fe}_{3} \mathrm{O}_{4} @ N G$ 
nanocomposites. The as-prepared nanocomposites with surfacetailorable functionalities were used for target drug delivery systems. ${ }^{35}$ Therefore, the RPP method can also be adopted to prepare magnetic polymer nanomaterials with different structures. However, the reflux operation and post-treatment process make the RPP method slightly cumbersome.

\section{Magnetic polymer nanomaterials in ordinary proteomics applications}

Magnetic polymer nanomaterials manifest superior performance in protein separation (Fig. 3). In ordinary proteomics, the adsorption mechanisms of proteins mainly include electrostatic interactions, molecularly imprinted technique, metal ion coordination, and other strategies.

Electrostatic interactions are the main driving forces for ordinary proteome separation. Calatayud et al. performed the in-situ coating of magnetic nanoparticles (MNPs) with polyethyleneimine (PEI) (PEI-MNPs) and poly(acrylic acid) (PAA-MNPs) by a modified oxidative hydrolysis method. ${ }^{36}$ The PEI-MNP surface had a positive charge, whereas the PAA-MNP surface had a negative charge. These positively and negatively charged MNPs were immersed in a protein-rich biological medium, and the protein was well adsorbed on nanoparticle surfaces through charge interactions. Yang et al. had proposed a modified inverse emulsion cross-linking approach using genipin as a cross-linking agent to prepare uniform $\mathrm{Fe}_{3} \mathrm{O}_{4}$ /carboxymethyl chitosan (CMCS) composite nanospheres with high saturation magnetization. The surface potential of the nanospheres began to change with the change of $\mathrm{pH}$. Near the isoelectric point of lysozyme (Lyz), negatively charged $\mathrm{Fe}_{3} \mathrm{O}_{4} /$ CMCS adsorbed positively charged Lyz through charge interactions. ${ }^{27}$ Similarly, many other researchers have also used negatively charged materials to adsorb positively charged proteins. ${ }^{37-39}$ It is worth noting that although the adsorption process of proteins using charge interactions is relatively simple, the specific adsorption effect is not good. Impurities are often adsorbed on material surfaces due to charge interactions.

Molecularly imprinted polymers (MIPs) are also commonly used in protein adsorption. An MIP possesses imprinting sites in the synthetic polymer matrix of complementary functional groups and structures and exhibits many significant advantages. ${ }^{40}$ Li et al. used BSA, $N$-isopropylacrylamide (NIPAM), methacrylic acid (MAA; functional monomer), and $N, N^{\prime}$-methylenebisacrylamide (MBA; cross-linking agent) to form a complex on the surface of

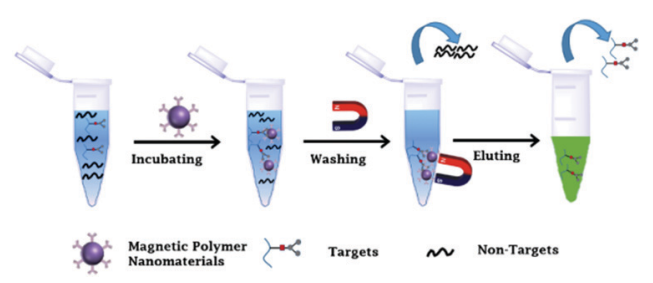

Fig. 3 Schematic illustration of the bioseparation process of magnetic polymer nanomaterials. magnetic nanoparticles and then removed BSA to form a molecularly imprinted composite. ${ }^{41}$ The as-prepared composite had a good adsorption capacity and specific recognition for template proteins. Lan et al. synthesized two molecularly imprinted materials for Lyz adsorption using poly(dihydroxyphenylacetic acid) (PDOPA) and polydopamine (PDA) as the polymer matrix. ${ }^{33}$ These Lyz-imprinted materials had a good imprinting effect on single protein solutions and also exhibited excellent ability to selectively recognize and capture Lyz from protein mixtures. Molecularly imprinted magnetic polymer nanomaterials with extreme specificity and universality are promising agents for capturing ordinary proteins; however, their preparation steps are complicated.

Moreover, the interactions between metal ions and proteins can also be effectively used in protein adsorption. Shukoor et al. reported a new type of $\mathrm{Ni}^{+}$-modified magnetic polymer nanomaterial for His-tagged protein separation. ${ }^{42}$ Due to the highaffinity binding interactions between $\mathrm{Ni}^{+}$ions and His-tagged proteins, the selective adsorption of His-tagged proteins was achieved by $\mathrm{Ni}^{+}$-modified magnetic polymer nanomaterials. Xie et al. used polymer spheres as the core, performed the surface modification of $\mathrm{Fe}_{3} \mathrm{O}_{4}$ nanoparticles, grew polymer brushes on the modified surface, and finally performed $\mathrm{Ni}^{+}$modification. The above materials were effective in adsorbing His-tagged proteins. ${ }^{43}$ Some common strategies have also been designed to capture proteins. ${ }^{44}$ The structure-selective protein adsorption strategy has also been employed to capture proteins. For example, Yang et al. used ligand-free $\mathrm{Fe}_{3} \mathrm{O}_{4} / \mathrm{CMCS}$ nanoclusters to selectively capture BHB from a model protein mixture. These ligand-free magnetic nanoclusters displayed an excellent structureselective protein adsorption ability to capture other proteins structurally similar to BHB, such as LYZ and CTP. ${ }^{45}$

\section{Magnetic polymer nanomaterials in glycoproteomics}

As one of the most common and critical protein PTMs, glycosylation is involved in multiple biological activities and cellular processes. ${ }^{46,47}$ Abnormal glycosylation processes, such as aberrant glycan structures and mismatched glycosylation sites, are closely related to cancer and diabetes. ${ }^{48,49}$ In order to meet the demands of mass spectrometry analyses, the pre-enrichment of glycoproteins or glycopeptides from complicated systems is imperative. Numerous approaches, such as hydrazide chemistry, boronic acid affinity chromatography, hydrophilic interaction liquid chromatography (HILIC), and molecular imprinting, have been developed for glycoprotein/glycopeptide enrichment. In the current section, magnetic polymer nanomaterials designed for glycoprotein/glycopeptide enrichment are discussed.

\subsection{Boronic-acid-based magnetic polymer nanomaterials in glycoproteomics}

Boronic acid groups and cis-diol-containing glycoproteins/glycopeptides can form stable and reversible covalent bonds through pH adjustment. ${ }^{50,51}$ Based on this mechanism, boronic acids can 
be used to fabricate affinity materials for the enrichment of glycoproteins/glycopeptides. Among them, phenylboronic acid (PBA) is most widely used in glycoproteomics. However, conventional PBA-based materials prepared using the small molecule modification strategy face many problems, such as low adsorption capacity, poor selectivity, and low sensitivity. ${ }^{52-54}$ Boronic acid-based magnetic polymer nanomaterials, possessing abundant affinity sites and high specific surface area for interactions, can significantly increase enrichment efficiency. Therefore, various PBA-functionalized magnetic polymer nanomaterials have been developed in recent years. Generally, two strategies are adopted to prepare PBA-functionalized magnetic polymer nanomaterials: (1) polymerization of PBA-containing monomers on the surface of magnetic nanoparticles and (2) modification of PBA on polymers. Our group prepared a novel $\mathrm{Fe}_{3} \mathrm{O}_{4} /$ carboxymethylated chitosan/poly(3-acrylaminophenylboronic acid) (dubbed $\mathrm{Fe}_{3} \mathrm{O}_{4} / \mathrm{CMCS} /$ PAAPBA) nanosphere by the surface-initiated ATRP method (Fig. 4A). ${ }^{55}$ The prepared $\mathrm{Fe}_{3} \mathrm{O}_{4} / \mathrm{CMCS} / \mathrm{PAAPBA}$ nanospheres possessed a uniform morphology and excellent magnetic properties. Due to the introduction of PAAPBA, these $\mathrm{pH}$-responsive $\mathrm{Fe}_{3} \mathrm{O}_{4} / \mathrm{CMCS} / \mathrm{PAAPBA}$ nanospheres could reversibly capture and release glycoproteins with high selectivity and recyclability in a pure protein, a model protein mixture, and a biological sample. Recently, $\mathrm{Fe}_{3} \mathrm{O}_{4} @ \mathrm{SiO}_{2} @$ @poly(2-aminoethyl methacrylate hydrochloride)-4-carboxyphenylboronic acid ( $\mathrm{Fe}_{3} \mathrm{O}_{4} @ \mathrm{SiO}_{2} @ P A M A-$ CPBA) nanoparticles have been prepared via surface-initiated ATRP. Owing to the synergistic effects of intermolecular B-N bond-based phenylboronic acid affinity, electrostatic interaction, and polymer brush structure, $\mathrm{Fe}_{3} \mathrm{O}_{4} @ \mathrm{SiO}_{2} @ P A M A-C P B A$ nanoparticles exhibited selectively capture capacity toward glycoproteins under neutral or slightly acidic conditions. The captured glycoproteins were released in alkaline solution because electrostatic repulsions between glycoproteins and nanoparticles were larger than phenylboronic acid affinity, showing an excellent adsorption capacity and selectivity for glycoproteins. ${ }^{56}$

In order to further enhance enrichment capabilities, hydrophilic components are integrated into boronic acid-based magnetic polymer nanomaterials. In the first strategy, boric acid monomers and hydrophilic monomers are copolymerized to enhance the capture performance. Zhang et al. produced hydrophilic $\mathrm{Fe}_{3} \mathrm{O}_{4}$ @$\mathrm{P}(\mathrm{AAPBA}$-comonomer) nanoparticles through copolymerization of two monomers of AAPBA and a hydrophilic functional monomer (Fig. 4B). ${ }^{57}$ Due to the introduction of hydrophilic molecules, the obtained $\mathrm{Fe}_{3} \mathrm{O}_{4} @ \mathrm{P}(\mathrm{AAPBA}$-comonomer) nanoparticles showed better binding capacity for glycoproteins. The other strategy is to introduce hydrophilic substrate materials to form boronic acid-based magnetic polymer nanomaterials. $\mathrm{Su}$ et al. used hydrophilic graphene oxide to prepare $\mathrm{Fe}_{3} \mathrm{O}_{4}-\mathrm{GO} @ P A A P B A$ as a novel matrix for glycoproteome analyses. ${ }^{58}$ Large adsorption capacities for glycoproteins OVA and Trf have been achieved.

Recently, boronic acid derivatives have been gradually developed for the enrichment of glycoproteins/glycopeptides. Among them, 3-carboxybenzoboroxole (CBX) having a higher affinity for glycoproteins and a lower $\mathrm{p} K_{\mathrm{a}}$ value (6.9) is used as a powerful functional molecule to prepare boronate affinity materials. Wu et al. designed and prepared a CBX-modified magnetic dendrimer nanocomposite to enhance glycopeptide enrichment. After enrichment, a total of 1302 glycoproteins with 3185 glycosylation sites were identified in MCF7 cells. ${ }^{59}$ Wang et al. developed PEI-assisted 3-carboxybenzoboroxole-functionalized magnetic nanoparticles to efficiently capture cis-diol-containing flavonoids under neutral conditions. ${ }^{60}$ Zhang et al. synthesized CBX-functionalized

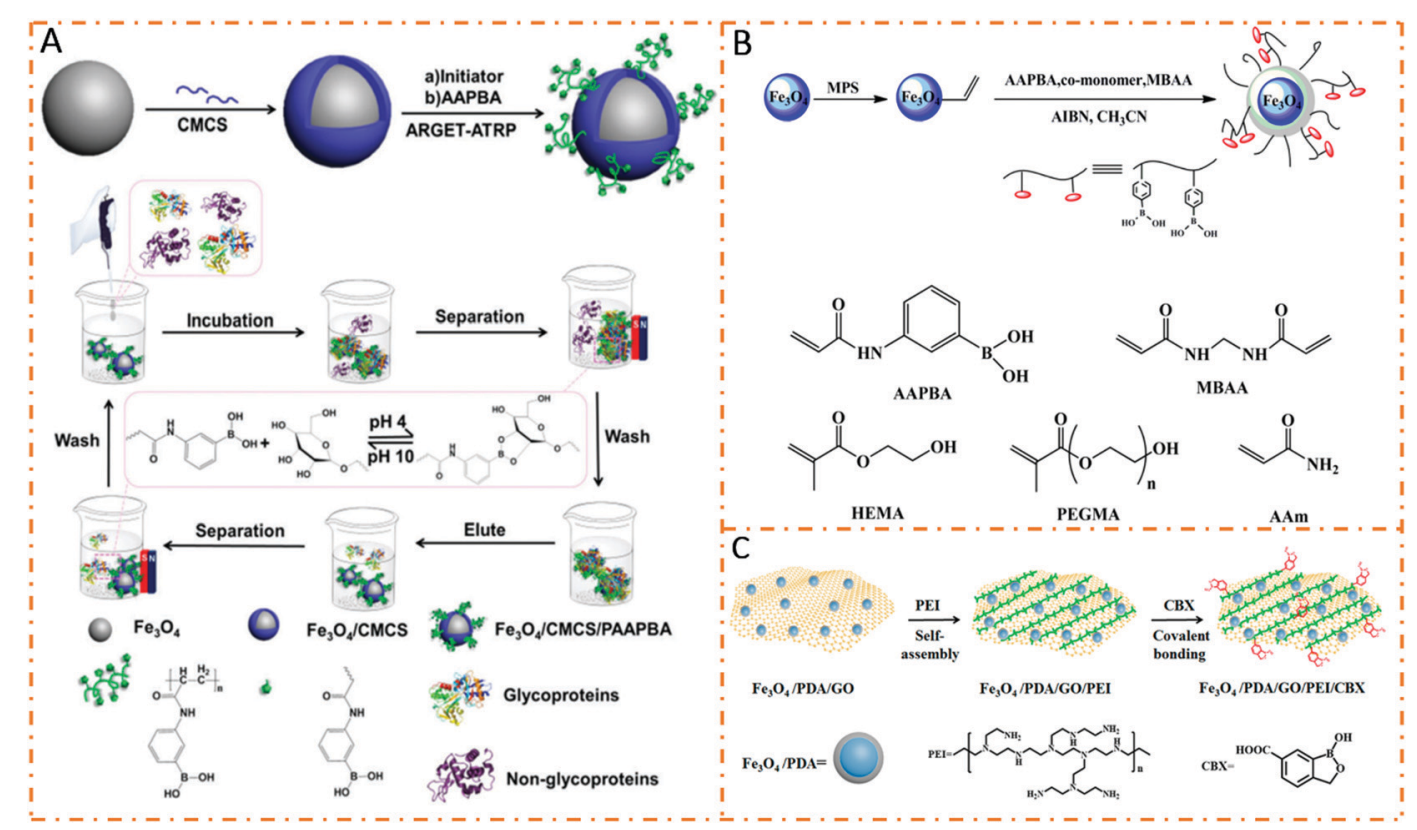

Fig. 4 Schematic illustration of the preparation and protein separation procedures of magnetic polymer nanomaterials. (A) Fe $\mathrm{O}_{4} / \mathrm{CMCS}_{\mathrm{PAAPBA}}$. Reproduced from ref. 55 with permission from the Royal Society of Chemistry. (B) $\mathrm{Fe}_{3} \mathrm{O}_{4}$ (AP(AAPBA-co-monomer). Reprinted from ref. 57 with permission from Copyright American Chemical Society. (C) $\mathrm{Fe}_{3} \mathrm{O}_{4} / \mathrm{PDA} / \mathrm{GO} / \mathrm{PEI} / \mathrm{CBX}$. Reprinted from ref. 61 with permission from Copyright American Chemical Society. 
polyethylenimine (PEI)-modified magnetic graphene oxide nanocomposites (dubbed $\mathrm{Fe}_{3} \mathrm{O}_{4} / \mathrm{PDA} / \mathrm{GO} / \mathrm{PEI} / \mathrm{CBX}$ ) for human plasma glycoprotein enrichment under physiological conditions (Fig. 4C). ${ }^{61}$ Due to the low $K_{\mathrm{a}}$ value $(-6.9)$, the resultant $\mathrm{Fe}_{3} \mathrm{O}_{4} / \mathrm{PDA} / \mathrm{GO} / \mathrm{PEI} /$ CBX nanocomposites could enrich glycoproteins under physiological conditions even in real human plasma. In addition, the binding capacity of the nanocomposites for HRP glycoprotein was much higher than those of previously reported affinity materials due to the PEI polymer-assisted multivalent binding.

\subsection{Hydrazide-chemistry-based magnetic polymer nanomaterials in glycoproteomics}

Hydrazide chemistry is also a specific and highly efficient method for glycoprotein/glycopeptide enrichment. In comparison to boronic acid, hydrazide chemistry can only be applied to $\mathrm{N}$-linked glycoprotein/glycopeptide isolation, resulting in relatively higher specificity. ${ }^{62-64}$ The enrichment mechanism of hydrazide chemistry proposed by Liu et al. is displayed in Fig. 5A. ${ }^{65}$ First, cis-diol parts of glycoproteins/glycopeptides are translated into aldehydes by oxidation reactions. Second, aldehydes react with hydrazide groups to form covalent bonds. Third, the captured glycoproteins/glycopeptides are released by PNGase F, which specifically cut $N$-glycans. Traditional affinity materials prepared by small-molecule modification strategies suffer from the low grafting density of hydrazide units, resulting in poor enrichment performance. In order to increase hydrazide affinity sites, various hydrazide-functionalized magnetic polymer nanomaterials have been developed. Lu et al. prepared a core-shell magnetic

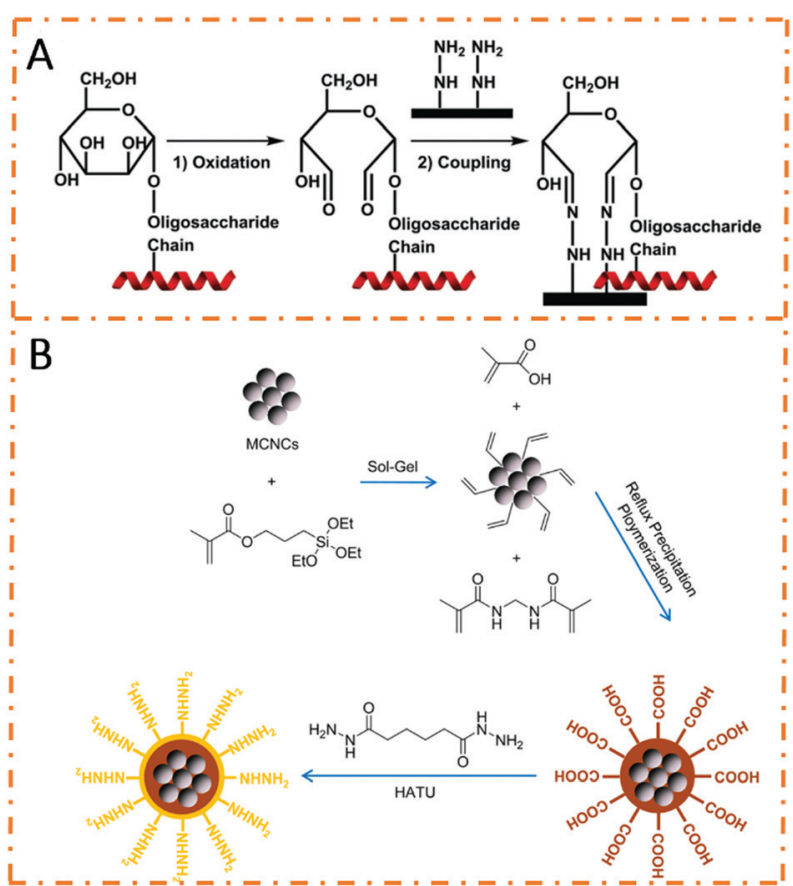

Fig. 5 (A) Binding mechanism of hydrazide chemistry for glycopeptide enrichment. Reprinted from ref. 65 with permission from Copyright Wiley-VCH. (B) Schematic illustration of the preparation procedures of $\mathrm{Fe}_{3} \mathrm{O}_{4}$ (apoly(methacrylic hydrazide). Reprinted from ref. 66 with permission from Copyright American Chemical Society. nanocomposite, in which both the magnetic core and the polymer shell were modified with abundant hydrazide groups, by reflux precipitation polymerization and a post-synthetic modification strategy (Fig. 5B). ${ }^{66}$ The as-prepared $\mathrm{Fe}_{3} \mathrm{O}_{4} @ \mathrm{PMAH}$ nanocomposites exhibited excellent glycopeptide enrichment performance due to the abundant hydrazide affinity sites. For standard glycopeptide enrichment, the $\mathrm{Fe}_{3} \mathrm{O}_{4} @ \mathrm{PMAH}$ nanocomposites improved the signal-to-noise ratio by more than five times that of commercial hydrazide resin.

In addition, after enrichment, 175 unique glycopeptides corresponding to 63 glycoproteins were identified from the serum of a colorectal cancer patient. Qian et al. prepared hydrazide-modified polymer chain-coated magnetic nanoparticles by the surfaceinitiated ATRP method. ${ }^{67}$ Thanks to the high efficiency of the ATRP method, the density of hydrazide groups was much higher than that of conventional affinity materials with single-layered hydrazide groups. Therefore, the obtained nanoparticles were endowed with outstanding sensitivity and selectivity toward glycopeptides. A total of 511 unique glycopeptides were detected from mouse liver tissues after enrichment. Generally, hydrazide-based affinity materials possess high specificity for glycopeptide/glycoprotein enrichment. However, hydrazide chemistry is relatively time-consuming and tedious during the pre-enrichment processing of samples as compared to boronic acid chemistry.

\subsection{Hydrophilic-interaction-based magnetic polymer nanomaterials in glycoproteomics}

Hydrophilic interaction chromatography (HILIC) is a normal-phase chromatographic mode based on a polar stationary phase and a mobile phase with medium or weak polarity. ${ }^{68}$ Normally, the polar stationary phase retains the polar solutes due to its higher polarity than the mobile phase. The partitioning mechanism between the stagnant layer of water which results in a hydrated polar stationary phase and the dynamic mobile phase is postulated to be the retention mechanism of HILIC initially. The hydrogen-bonding and electrostatic interactions are discovered to be two main contributors to HILIC retention. Glycopeptides can be easily extracted by HILIC based on different hydrophilic properties of glycopeptides and non-glycopeptides. Therefore, HILIC-based affinity materials are widely employed in glycoproteomics due to their high glycopeptide coverage, excellent reproducibility, and mild enrichment conditions. ${ }^{69-73}$ Hydrophilic interaction-based magnetic polymer nanomaterials have attracted great attention for glycopeptide enrichment in recent years. Flexible polymeric chains promote the affinity interactions between glycopeptides and polymer molecules, and the adjustable molecular weight and grafting thickness of polymers affect the formation of hydration layers. In addition, various suitable polymer molecules have been developed for HILIC-based affinity materials. ${ }^{74}$ Among them, carbohydrate and zwitterionic molecules manifest excellent performances in glycopeptide enrichment applications.

Poly(ethylene glycol) (PEG) and amino-based polymers are two typical types of hydrophilic polymeric molecules and are widely used in HILIC-based affinity materials. Wang et al. designed and synthesized a kind of dendrimer-modified magnetic graphene@polydopamine@poly(amidoamine) composite 
(dubbed magG@PDA@PAMAM) for glycopeptide enrichment (Fig. 6A). ${ }^{75}$ Due to the superhydrophilicity of PAMAM, the resultant magG@PDA@PAMAM composites had outstanding sensitivity ( $1 \mathrm{fmol} \mathrm{mL}^{-1}$ ) and high selectivity (HRP: BSA molar ratio $=1: 100$ ) for glycopeptide enrichment. Jiang et al. designed and prepared PEG-modified magnetic composites (dubbed GO/ $\mathrm{Fe}_{3} \mathrm{O}_{4} / \mathrm{Au} / \mathrm{PEG}$ ) with high hydrophilic properties and resistance to non-specific adsorption. ${ }^{76}$ Therefore, these $\mathrm{GO} / \mathrm{Fe}_{3} \mathrm{O}_{4} / \mathrm{Au} / \mathrm{PEG}$ composites possessed excellent enrichment performance for glycopeptides in complex biological samples. A total of 255 glycopeptides were identified from human plasma after the enrichment process. Recently, Deng et al. prepared PEG-functionalized magnetic nanomaterials through covalent bonding between titanium and sulfur (denoted as $\mathrm{Fe}_{3} \mathrm{O}_{4} @ \mathrm{TiO}_{2} @ \mathrm{PEG}$. ${ }^{77}$ Surprisingly, the $\mathrm{Fe}_{3} \mathrm{O}_{4} @ \mathrm{TiO}_{2} @$ @PEG nanomaterials could enrich 300 intact glycopeptides from only $2 \mu \mathrm{L}$ of human serum.

Maltose molecule, as a typical hydrophilic molecule, is widely used to modify magnetic polymer nanomaterials for designing HILIC-based affinity materials. As a consequence, various maltosefunctionalized magnetic polymer nanomaterials with excellent performance have been designed for glycopeptide enrichment. Zou et al. prepared maltose-functionalized magnetic nanomaterials (denoted as dM-MNPs) by azide-alkynyl click reactions. ${ }^{78}$ The dMMNPs exhibited good performance for glycopeptide enrichment by the HILIC method. Li et al. prepared maltose-functionalized polyethyleneimine (PEI)-coated magnetic nanospheres (dubbed $\mathrm{Fe}_{3} \mathrm{O}_{4^{-}}$ PEI-maltose) by the "click chemistry" modification method. ${ }^{79}$ Due to the presence of hydrophilic maltose molecules and branched polyethyleneimine, the $\mathrm{Fe}_{3} \mathrm{O}_{4}-\mathrm{PEI}$-maltose nanospheres revealed splendid enrichment performances in model proteins. In addition, 1567 unique glycopeptides were identified from $60 \mu \mathrm{g}$ of a protein sample extracted from mouse liver after enrichment by $\mathrm{Fe}_{3} \mathrm{O}_{4}-\mathrm{PEI}-$ maltose nanospheres. In addition to the above examples, many maltose-modified magnetic polymer nanomaterials are also used for glycopeptide enrichment. ${ }^{80,81}$

Taking advantage of the superhydrophilicity and ultra-low biofouling capabilities of zwitterionic (ZIC) molecules, thicker hydration layers can be formed around terminal groups of
ZIC-based nanomaterials. Therefore, ZIC-HILIC affinity materials exhibit stronger hydrophilic interactions toward glycopeptides. Among them, cysteine and (2-(methacryloyloxy)ethyl)-dimethyl-(3sulfopropyl)ammonium hydroxide (MSA) are the most widely used zwitterionic molecules for glycopeptide enrichment. ${ }^{82,83}$ In order to further strengthen the glycopeptide capture effectiveness with multilayer functional molecules, recent research works have revealed the application of ZIC-based magnetic polymer nanomaterials for sample pretreatment in glycoproteomics. Zhao et al. designed and prepared cysteine (Cys)-functionalized magnetic polymer nanomaterials to effectively separate glycopeptides from complex samples. PGMA was prepared on the surface of the $\mathrm{Fe}_{3} \mathrm{O}_{4}$ magnetic nanoparticles by one-step reflux-precipitation polymerization. After the modification of $\mathrm{Au}$ nanoparticles, zwitterionic cysteine was successfully introduced to obtain $\mathrm{Fe}_{3} \mathrm{O}_{4} @$ @GMA@Au-cys nanomaterials (Fig. 6B) ${ }^{84}$ After the treatment with $\mathrm{Fe}_{3} \mathrm{O}_{4} @ P G M A @ A u-c y s$ nanomaterials, a total of 411 unique glycoproteins were identified from a $75 \mu \mathrm{g}$ protein sample extracted from mouse liver. Chen et al. reported a kind of PMSA-coated $\mathrm{Fe}_{3} \mathrm{O}_{4} @ \mathrm{SiO}_{2}$ nanosphere for glycopeptide enrichment. ${ }^{85}$ The as-prepared $\mathrm{Fe}_{3} \mathrm{O}_{4} @ \mathrm{SiO}_{2} @ \mathrm{PMSA}$ nanospheres exhibited high enrichment recovery (73.6\%), extremely high sensitivity $(0.1 \mathrm{fmol})$, and binding capacity (100 $\mathrm{mg} \mathrm{g}^{-1}$ ) for glycopeptide enrichment from a tryptic digest of human IgG. In addition, a total of 458 glycoproteins with $905 \mathrm{~N}$-glycosylated sites were identified from mouse liver extracts. Recently, Ji et al. reported another PMSAbased magnetic composite (denoted as $\mathrm{Fe}_{3} \mathrm{O}_{4} @ \mathrm{PMSA}$ ) for the highly specific enrichment of glycopeptides. ${ }^{86}$ A summary of HILIC-based magnetic polymer nanomaterials is presented in Table 1 . The development and design of various functional molecules with stronger hydrophilic properties will further promote the application of magnetic polymer nanomaterials in glycoproteomics.

\subsection{Molecularly imprinted magnetic polymer manomaterials in glycoproteomics}

The molecular imprinting technique, which creates templateshaped cavities with high specificity toward target molecules, is widely used in the fields of separation and purification.

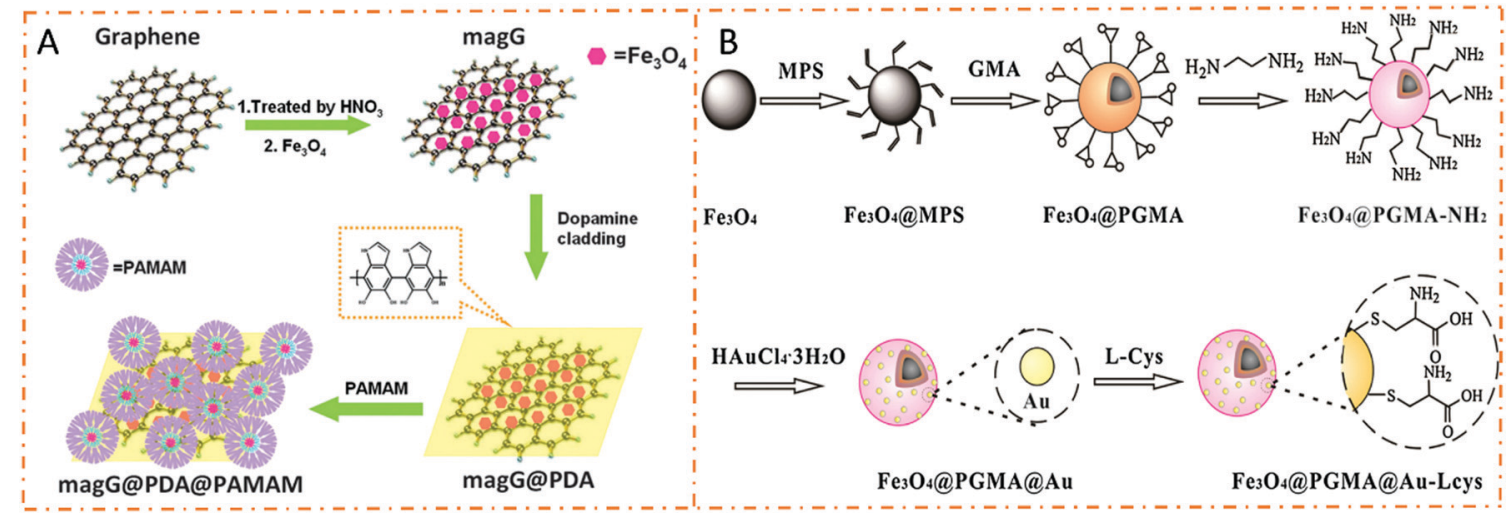

Fig. 6 Schematic illustration of the preparation procedures of hydrophilic interaction based magnetic polymer nanomaterials in glycoproteomics.

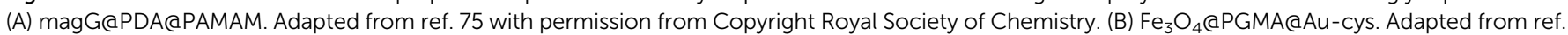
84 with permission from Copyright Elsevier B.V. 
Table 1 Representative display of hydrophilic interaction based magnetic polymer nanomaterials in glycoproteomics

\begin{tabular}{|c|c|c|c|c|c|c|}
\hline Nanomaterials & Polymer linkers & Hydrophilic moieties & Practical samples & $\begin{array}{l}\text { Identified } \\
\text { glycoproteins }\end{array}$ & $\begin{array}{l}\text { Identified } \\
\text { glycopeptides }\end{array}$ & Ref. \\
\hline magG@PDA@PAMAM & PDA & PAMAM & Human serum & - & 11 & 75 \\
\hline $\mathrm{GO} / \mathrm{Fe}_{3} \mathrm{O}_{4} / \mathrm{Au} / \mathrm{PEG}$ & PEI & PEG & Human serum & 127 & 255 & 76 \\
\hline dM-MNPs & Dendrimers & Maltose & Mouse liver & 418 & 653 & 78 \\
\hline $\mathrm{Fe}_{3} \mathrm{O}_{4}-\mathrm{PEI}$-maltose & PEI & Maltose & Mouse liver & 684 & 1567 & 79 \\
\hline $\mathrm{Fe}_{3} \mathrm{O}_{4}$-PEI-pMaltose & PEI & Maltose & Human renal mesangial cell & 323 & 449 & 80 \\
\hline $\mathrm{Fe}_{3} \mathrm{O}_{4} @ \mathrm{SiO}_{2} @ \mathrm{PMSA}$ & - & PMSA & Mouse liver & 458 & - & 85 \\
\hline
\end{tabular}

Molecularly imprinted polymers (MIPs) are designed and prepared by copolymerizing suitable functional monomers in the presence of templates. MIPs are considered as attractive candidates due to their outstanding advantages, such as high specificity, reversible binding capacity, and applicability in harsh environments. In glycoprotein separation applications, combining molecular imprinting and the boric acid affinity technology is a common strategy to achieve synergistic selectivity toward glycoproteins. Therefore, various molecularly imprinted magnetic polymer nanomaterials with boric acid affinity sites have been reported for glycoprotein separation. Xie et al. prepared magnetic MIP microspheres by the ATRP method using 2-(dimethylamino)ethyl methacrylate and 4-vinylphenylbronic acid as monomers. Meanwhile, the glycoprotein ovalbumin (OVA) was employed as the template (Fig. 7). ${ }^{87}$ The microspheres showed excellent performance in capturing glycoprotein OVA. Sun et al. synthesized magnetic molecularly imprinted microspheres by employing polydopamine as the polymer matrix and glycoprotein horseradish peroxidase (HRP) and OVA as dual templates. ${ }^{88}$ The as-prepared microspheres could simultaneously and selectively capture HRP and OVA. Using the same strategy, numerous molecularly imprinted magnetic polymer nanomaterials have been developed to selectively capture glycoproteins. ${ }^{89-91}$ However, these nanomaterials can only be used to capture a limited amount of glycoproteins. In addition, the

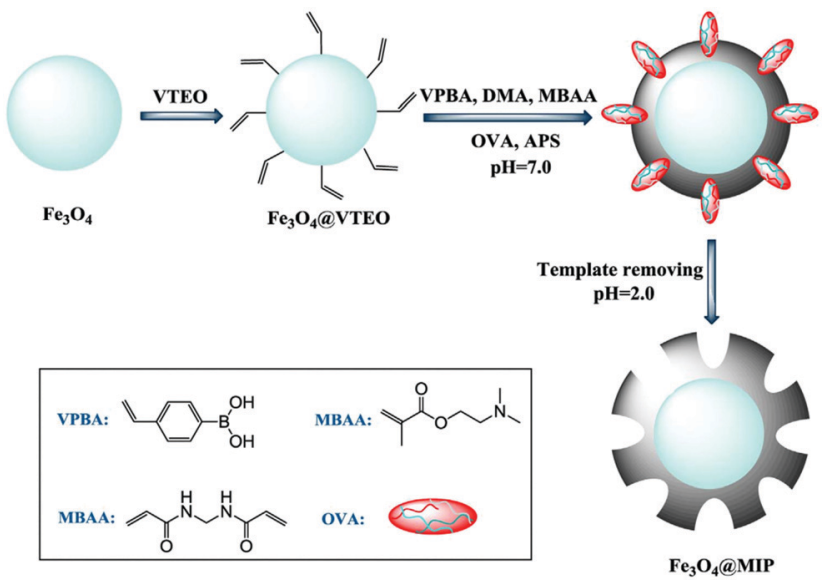

Fig. 7 Schematic illustration of the preparation procedures of molecularly imprinted magnetic polymer nanomaterials ( $\mathrm{Fe}_{3} \mathrm{O}_{4} \mathrm{QMIP}$ ). Reprinted from ref. 87 with permission from Copyright Elsevier B.V. molecular imprinting technique is not suitable for glycopeptide enrichment. The lack of universality is a major obstacle to the application of molecular imprinting technology in glycoproteomics.

\section{Magnetic polymer nanomaterials in phosphoproteomics}

As another ubiquitous PTM, reversible protein phosphorylation plays a vital role in regulating multiple biological processes. ${ }^{92}$ Abnormal phosphorylation is closely associated with various diseases including cardiovascular diseases, Alzheimer's disease (AD), and cancer. ${ }^{93,94}$ The effective separation and enrichment of phosphopeptides prior to MS analyses is the prerequisite to analyze phosphoproteomics-related biological and pathological processes. Numerous materials and methods have been developed to selectively enrich phosphopeptides. Affinity methods are mainly divided into immobilized-metal ion affinity chromatography (IMAC), metal oxide affinity chromatography (MOAC), amine-based affinity materials, and some combinations of these methods. ${ }^{95}$ In order to enhance the enrichment performance of these traditional materials, various IMAC, MOAC, and aminebased magnetic polymer affinity materials have been developed for phosphoproteomics. The present section focuses on the applications of magnetic polymer nanomaterials in phosphoproteomics.

\subsection{IMAC-based magnetic polymer nanomaterials in phosphoproteomics}

IMAC is a widely used enrichment technique in phosphoproteomics. Metal cations interact with phosphate groups through electrostatic interactions and chelation. In order to fabricate IMAC affinity materials, matrix supports carrying chelating ligands are first prepared, and then metal cations are immobilized on chelating ligands. Polymers with abundant functional groups can serve as novel chelating ligands with higher chelating ability, strength, and capacity.

PDA is a commendable linker for immobilizing metal ions because it can offer good hydrophilicity, biocompatibility, and abundant active amino and hydroxyl groups. ${ }^{96}$ Sun et al. developed PDA-coated magnetic graphene/mesoporous silica composites for titanium immobilization (denoted as $\mathrm{Ti}^{4+}$-MGMSs) to selectively enrich phosphopeptides (Fig. 8A). ${ }^{97}$ The resultant $\mathrm{Ti}^{4+}$-MGMSs presented high enrichment sensitivity $(\beta$-casein tryptic digest 


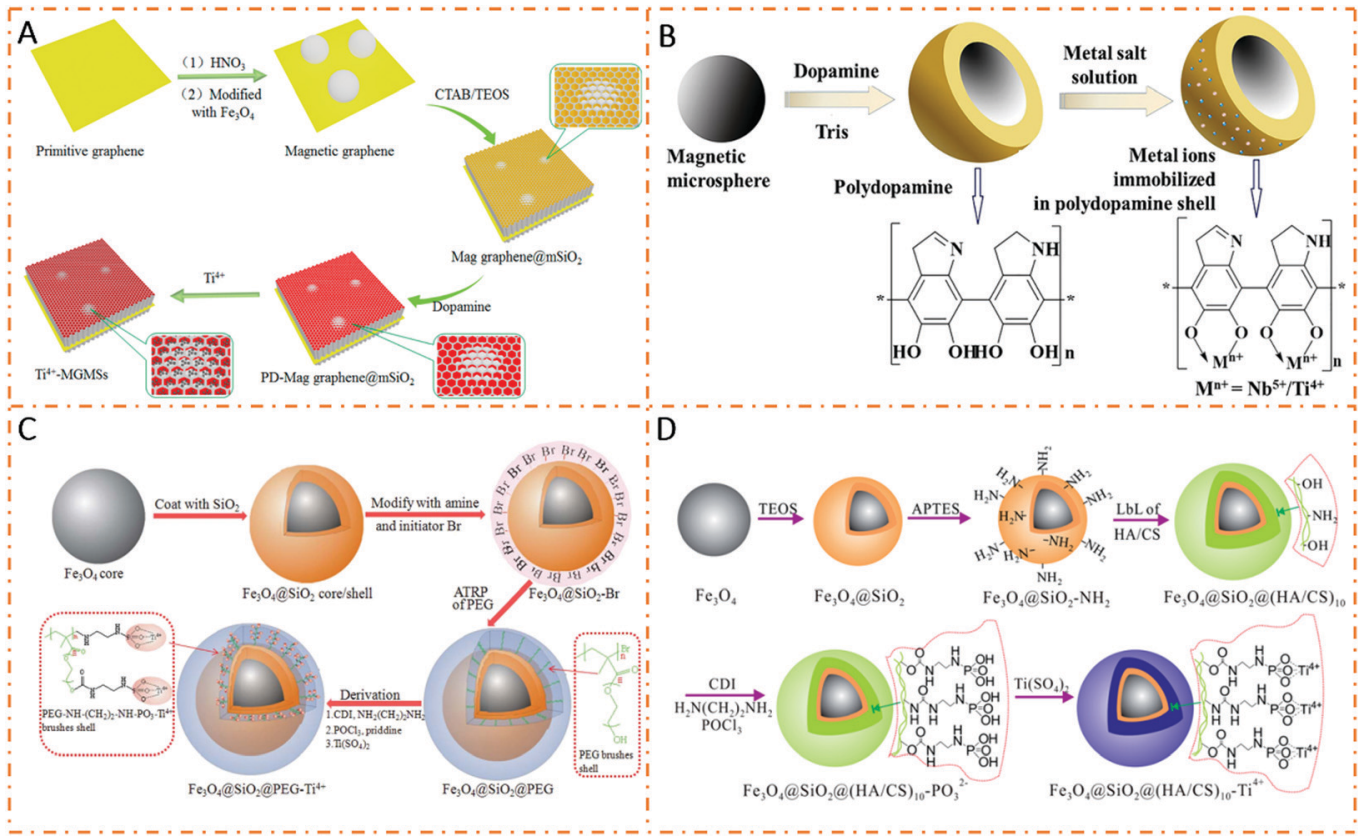

Fig. 8 Schematic illustration of the preparation procedures of IMAC-based nanomaterials. (A) $\mathrm{Ti}^{4+}-\mathrm{MGMSs}$. Reproduced from ref. 97 with permission from Copyright American Chemical Society. (B) $\mathrm{Fe}_{3} \mathrm{O}_{4} \mathrm{aPDA}-\mathrm{Ti} / \mathrm{Nb}$. Reprinted with permission 100. (C) $\mathrm{Fe}_{3} \mathrm{O}_{4} \mathrm{QSSiO}_{2} \mathrm{aPEG}_{\mathrm{T}} \mathrm{Ti}^{4+}$. Adapted from ref. 101 with permission from Copyright Royal Society of Chemistry. (D) $\mathrm{Fe}_{3} \mathrm{O}_{4} \mathrm{QSSiO} \mathrm{O}_{2} \mathrm{a}(\mathrm{HA} / \mathrm{CS}) 10-\mathrm{Ti}^{4+}$. Reprinted with permission from ref. 102.

(0.5 fmol $\mu \mathrm{L}^{-1}$ )) and selectivity (mass ratio of $\beta$-casein to BSA (1:500)). In addition, Lin et al. reported a kind of magG@PDA$\mathrm{Sn}^{4+}$ composite by immobilizing $\mathrm{Sn}^{4+}$ (Iv) ions on polydopaminecoated magnetic graphene. ${ }^{98}$ The obtained magG@PDA-Sn ${ }^{4+}$ possessed large surface area, fast magnetic response performance, outstanding hydrophilicity, and strong metal ion bonding ability, leading to high sensitivity ( $\beta$-casein, $8 \mathrm{fmol}$ ) and excellent selectivity (molar ratio of $\beta$-casein to BSA $(1: 1000))$ toward phosphopeptides. Moreover, magG@PDA-Sn ${ }^{4+}$ was used to capture endogenous phosphopeptides from human saliva, and a total of 20 phosphopeptides were identified after enrichment. Jiang et al. immobilized different metal ions $\left(\mathrm{Nb}^{5+}, \mathrm{Ti}^{4+}, \mathrm{Zr}^{4+}, \mathrm{Ga}^{3+}, \mathrm{Y}^{3+}, \mathrm{In}^{3+}\right.$, $\mathrm{Ce}^{4+}$, and $\mathrm{Fe}^{3+}$ ) on PDA-coated $\mathrm{Fe}_{3} \mathrm{O}_{4}$ (denoted as $\mathrm{Fe}_{3} \mathrm{O}_{4} @$ @PDA-M $\left.{ }^{n+}\right){ }^{99}$ The microspheres functionalized with different metal ions presented diverse phosphopeptide enrichment efficiencies. Hence, $\mathrm{Fe}_{3} \mathrm{O}_{4} @$ @PDA-Nb ${ }^{5+}$ and $\mathrm{Fe}_{3} \mathrm{O}_{4}$ @ PDA-Ti ${ }^{4+}$ manifested great performances in capturing phosphopeptides with higher selectivity and enhanced sensitivity. Jiang et al. modified the $\mathrm{Fe}_{3} \mathrm{O}_{4} @ P D A$ microspheres with $\mathrm{Ti}(\mathrm{Iv})$ and $\mathrm{Nb}(\mathrm{v})$ ions to prepare $\mathrm{Fe}_{3} \mathrm{O}_{4} @ P D A-\mathrm{Ti} / \mathrm{Nb}$ composites (Fig. 8B). ${ }^{100}$ Due to the complementary electrostatic interactions among phosphopeptides, binary $\mathrm{Fe}_{3} \mathrm{O}_{4} @$ PDA-Ti/Nb microspheres displayed good enrichment efficiency with higher selectivity and sensitivity as compared to single metal ion-loaded microspheres $\left(\mathrm{Fe}_{3} \mathrm{O}_{4} @ P D A-T i\right.$ and $\left.\mathrm{Fe}_{3} \mathrm{O}_{4} @ P D A-\mathrm{Nb}\right)$ and their physical mixture.

Numerous polymers have also emerged as novel ligands to increase the chelating ability for phosphoproteomics research. Zhao et al. introduced a titanium phosphate moiety on a poly(ethylene glycol)methacrylate (PEG) brush-decorated $\mathrm{Fe}_{3} \mathrm{O}_{4} @ \mathrm{SiO}_{2}$ core-shell nanoparticle (denoted as $\mathrm{Fe}_{3} \mathrm{O}_{4} @ \mathrm{SiO}_{2} @$ PEG-Ti ${ }^{4+}$ ) (Fig. 8C). ${ }^{101}$ Due to the enhanced chelating capacity of thick PEG brushes, the $\mathrm{Fe}_{3} \mathrm{O}_{4} @ \mathrm{SiO}_{2} @ \mathrm{PEG}-\mathrm{Ti}^{4+}$ IMAC nanoparticle demonstrated a low limit of detection ( $\beta$-casein, $0.5 \mathrm{fmol})$ with an excellent specificity towards a tryptic digest of $\alpha$-casein and BSA (molar ratio of up to $1: 2000$ ). In the analysis of the real biological samples (Arabidopsis), a superior enrichment performance of $\mathrm{Fe}_{3} \mathrm{O}_{4} @ \mathrm{SiO}_{2} @ \mathrm{PEG} \mathrm{Ti}^{4+}$ (2447) was achieved compared to those of $\mathrm{Fe}_{3} \mathrm{O}_{4} @ \mathrm{SiO}_{2}-\mathrm{Ti}^{4+}$ (1186) and commercial $\mathrm{TiO}_{2}$ microspheres (961). In order to further strengthen the chelation of metal ions, multilayer chelating ligands were developed for metal ion immobilization. For instance, Xiong et al. introduced a titanium phosphate moiety on a cross-linked multilayer polysaccharide (hyaluronate (HA) and chitosan (CS)) to enhance the chelating ability. Meanwhile, the multilayer titanium phosphate modified polysaccharide was coated on the $\mathrm{Fe}_{3} \mathrm{O}_{4} @ \mathrm{SiO}_{2}$ nanoparticle to obtain the $\mathrm{Fe}_{3} \mathrm{O}_{4} @$ @$\mathrm{SiO}_{2} @(\mathrm{HA} / \mathrm{CS}) 10-\mathrm{Ti}^{4+}$ nanocomposite (Fig. 8D). ${ }^{102}$ Due to the hydrophilic properties and high $\mathrm{Ti}^{4+}$ binding capacity of the multilayer chelating ligands, the prepared nanocomposites showed excellent enrichment performance in model proteins. In addition, after treatment with the above nanocomposites, four phosphopeptides from human serum and eleven phosphopeptides from nonfat milk were successfully identified. Ma et al. modified poly(ethylene glycol methacrylate phosphate) (PEGMP) and poly(methylacrylic acid) (PMAA) to a magnetic colloid nanocrystal cluster (MCNC) core through two-step distillation-precipitation polymerization followed by $\mathrm{Ti}^{4+}$ immobilization on the surface of the PEGMP shell (dubbed MCNC@PMAA@PEGMP-Ti ${ }^{4+}$ ) for phosphopeptide enrichment. ${ }^{103}$ Due to the high grafting density of chelating ligands, the MCNC@PMAA@PEGMP-Ti ${ }^{4+}$ composite microsphere revealed remarkable selectivity ( $\beta$-casein/BSA molar ratio $=1: 500$ ), sensitivity ( $\beta$-casein, $50 \mathrm{fmol}$ ), and excellent recovery (87\%) toward phosphopeptide enrichment. Poly(vinylphosphonic acid) (PVPA) 
is also a commonly used polymer for chelating metal ions. For example, Wang et al. introduced poly(vinylphosphonic acid) (PVPA) shells on $\mathrm{SiO}_{2}$-coated $\mathrm{Fe}_{3} \mathrm{O}_{4}$ microspheres through a radical polymerization reaction to immobilize $\mathrm{Ce}$ (Iv) ions (denoted as $\mathrm{Fe}_{3} \mathrm{O}_{4}$ @$\left.\mathrm{SiO}_{2} @ P V P A-\mathrm{Ce}(\mathrm{Iv})\right)$ for phosphopeptide enrichment. ${ }^{104}$

In summary, the inherent performance of magnetic polymer nanomaterials strengthens the chelating ability of metal ions and enhances the enrichment capacity for phosphopeptides based on the IMAC method. The development and design of various chelating ligands with stronger chelating ability will further promote the application of IMAC-based magnetic polymer nanomaterials in phosphoproteomics.

\subsection{MOAC-based magnetic polymer nanomaterials in phosphoproteomics}

MOAC is another widely used enrichment strategy for phosphopeptides, and it works based on the reversible Lewis acid-base interactions between surface metal cations and phosphate groups. The in situ growth of metal oxides on magnetic polymer surfaces is the main strategy for MOAC-based magnetic polymer nanomaterial design, in which polymers act as growth sites. Liang et al. designed and prepared a functional graphene $/ \mathrm{Fe}_{3} \mathrm{O}_{4} / \mathrm{PDA} / \mathrm{TiO}_{2}$ composite for phosphopeptide enrichment. ${ }^{105}$ The polydopamine layer promoted the growth of $\mathrm{TiO}_{2}$ and decreased the non-specific adsorption to improve selectivity. The material possessed extremely high sensitivity ( $\beta$-casein, 0.2 amol) and selectivity ( $\beta$-casein/ BSA molar ratio $=1: 500$ ) toward phosphopeptides. Wang et al. prepared $\mathrm{Fe}_{x} \mathrm{O}_{y}$ and $\mathrm{ZrO}_{2}$ nanoparticles co-doped layered porous polyimide nanocomposites by a one-step strategy (denoted as $\left.\mathrm{PI}-\mathrm{Fe}_{x} \mathrm{O}_{y}-\mathrm{ZrO}_{2}\right) .{ }^{106}$ The layered and porous structure of the polymer offered abundant reaction sites for metallic oxide anchoring and provided a large specific surface area. The high doping of $\mathrm{ZrO}_{2}$ facilitated better adsorption performance toward phosphopeptides as compared to commercial titanium dioxide nanoparticles. In addition, multi metal oxides were immobilized on magnetic polymer materials to further improve the ability to capture phosphopeptides. Deng et al. integrated binary metal oxides $\left(\mathrm{ZrO}_{2}\right.$ and $\left.\mathrm{TiO}_{2}\right)$ into polydopamine-coated magnetic graphene to prepare the $\mathrm{magG} / \mathrm{PD} /(\mathrm{Zr}-\mathrm{Ti}) \mathrm{O}_{4}$ nanocomposites (Fig. 9). ${ }^{107}$ Compared with single metal oxide, the as-prepared magG/PD/(Zr-Ti)O $\mathrm{O}_{4}$ composites with binary metal oxides exhibited better enrichment efficiency. This affinity material showed extremely high enrichment performance for phosphopeptides from model proteins and real biological samples. In addition, there are many other MOAC-based magnetic polymer



Fig. 9 Schematic illustration of the preparation procedures of MOACbased nanomaterials (magG/PD/( $\mathrm{Zr}-\mathrm{Ti}) \mathrm{O}_{4}$ ). Reprinted from ref. 107 with permission from Copyright Wiley- $\mathrm{VCH}$. nanomaterials used in phosphoproteomics. ${ }^{108-111}$ A summary of IMAC/MOAC-based magnetic polymer nanomaterials used in phosphoproteomics is presented in Table 2 .

\subsection{Amine-based magnetic polymer nanomaterials in phosphoproteomics}

Amine-based affinity materials capture phosphopeptides based on the electrostatic attraction and hydrogen bonding interactions between amine groups and phosphate groups. Chen et al. used polyethyleneimine (PEI) to modify magnetic nanoparticles for the preparation of $\mathrm{Fe}_{3} \mathrm{O}_{4} @ \mathrm{SiO}_{2} @ P E I$ nanoparticles. ${ }^{112}$ The abundant amine groups on PEI interacted with phosphate groups, leading to high enrichment efficiency toward phosphopeptides. The detection limit for both $\alpha$-casein and $\beta$-casein was 5 fmol, and monophosphopeptides and multiphosphopeptides could be selectively enriched. Recently, our group introduced polyamidoamine dendrimers (PAMAM) to prepare (PAMAM)-grafted poly(methacrylic acid) (PMAA) brush-modified magnetic composite nanospheres

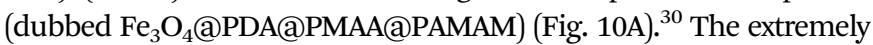
abundant amine groups of PAMAM-PMAA brushes and the magnetism of the $\mathrm{Fe}_{3} \mathrm{O}_{4}$ core endowed the composite nanospheres with high detection sensitivity ( $\beta$-casein, $1 \mathrm{fmol} \mathrm{mL^{-1 }}$ ) and excellent selectivity ( $\beta$-casein/BSA molar ratio $=1: 500)$. In addition, the nanospheres exhibited an amazing tunable capturing ability toward global phosphopeptides, monophosphopeptides, or merely multiphosphopeptides based on the tunable bonding strength between PAMAM and phosphate groups.

Guanidinium with three amine groups can also strongly interact with phosphate groups by forming steady salt bridge structures. Xiong et al. introduced guanidyl on poly(glycidyl methacrylate) (PGMA)-modified $\mathrm{Fe}_{3} \mathrm{O}_{4}$ microspheres (denoted as $\mathrm{Fe}_{3} \mathrm{O}_{4} @$ @PGMguanidyl) to selectively enrich global phosphopeptides or only multiphosphopeptides (Fig. 10B). ${ }^{113}$ Benefitting from the abundant guanidino groups, the composite microspheres achieved high enrichment performance for phosphopeptide enrichment. Notably, the $\mathrm{Fe}_{3} \mathrm{O}_{4}$ @PGMA-guanidyl possessed a flexible tunable enriching ability for global phosphopeptides or only multiphosphopeptides in both model protein and complex biological samples. Recently, our group fabricated $\mathrm{Fe}_{3} \mathrm{O}_{4} /$ polydopamine/poly(2-aminoethyl methacrylate hydrochloride)/arginine composite nanospheres $\left(\mathrm{Fe}_{3} \mathrm{O}_{4} / \mathrm{PDA} /\right.$ PAMA-Arg) that manifested tunable enrichment selectivity toward global phosphopeptides or multiphosphopeptides with extremely high detection sensitivity ( $\beta$-casein, $0.2 \mathrm{fmol}$ ) and selectivity $(\beta$-casein/BSA molar ratio $=1: 500)$ due to the abundant guanidyl and amino groups of PAMA-Arg brushes. ${ }^{31}$ Employing the materials, 1059 phosphopeptides including 923 monophosphopeptides (87.2\%) and 136 multiphosphopeptides (12.8\%) were successfully identified from a rat brain lysate digest. It can be seen that the adjustable enrichment performance for phosphopeptides makes the guanidyl-based magnetic polymer nanomaterials possess great application potential.

\subsection{Multi-strategy-based magnetic polymer nanomaterials in phosphoproteomics}

As different affinity materials exhibit different capturing abilities toward phosphopeptides, the integration of various materials into 
Table 2 Summary of the magnetic polymer nanomaterials based on IMAC/MOAC in phosphoproteomics

\begin{tabular}{|c|c|c|c|c|c|c|c|}
\hline Nanomaterials & $\begin{array}{l}\text { Main functional } \\
\text { moieties }\end{array}$ & Linkers & Selectivity & Sensitivity & Practical samples & $\begin{array}{l}\text { Identified } \\
\text { glycopeptides }\end{array}$ & Ref. \\
\hline $\mathrm{Ti}^{4+}$-MGMSs & $\mathrm{Ti}^{4+}$ & PDA & - & $0.5 \mathrm{fmol} \mu \mathrm{L}^{-1}$ & Human saliva & 14 & 97 \\
\hline magG@PDA-Sn ${ }^{4+}$ & $\mathrm{Sn}^{4+}$ & PDA & $\begin{array}{l}\beta \text {-Casein/BSA } \\
(\text { molar ratio }=1: 1000)\end{array}$ & $8 \mathrm{fmol}$ & Human saliva & 20 & 98 \\
\hline $\mathrm{Fe}_{3} \mathrm{O}_{4} @ P D A-\mathrm{M}^{n+}$ & $\begin{array}{l}\mathrm{Nb}^{5+}, \mathrm{Ti}^{4+}, \mathrm{Zr}^{4+}, \mathrm{Ga}^{3+} \\
\mathrm{Y}^{3+}, \mathrm{In}^{3+}, \mathrm{Ce}^{4+}, \mathrm{Fe}^{3+}\end{array}$ & PDA & $\begin{array}{l}\beta \text {-Casein/BSA } \\
(\text { molar ratio = } 1: 100)\end{array}$ & $2 \mathrm{fmol}$ & Nonfat milk & 16 & 99 \\
\hline $\mathrm{Fe}_{3} \mathrm{O}_{4} @ P D A-\mathrm{Ti} / \mathrm{Nb}$ & $\mathrm{Ti}^{4+} / \mathrm{Nb}^{5+}$ & PDA & $\begin{array}{l}\beta \text {-Casein/BSA } \\
(\text { mass ratio = } 1: 1000)\end{array}$ & $2 \mathrm{fmol}$ & Nonfat milk & 19 & 100 \\
\hline MCNC@PMAA@PEGMP-Ti ${ }^{4+}$ & $\mathrm{Ti}^{4+}$ & PMAA/PEGMP & $\begin{array}{l}\beta \text {-Casein/BSA } \\
(\text { molar ratio = } 1: 500)\end{array}$ & $50 \mathrm{fmol}$ & $\begin{array}{l}\text { Milk with a fat } \\
\text { content of about } 3 \%\end{array}$ & 10 & 103 \\
\hline $\mathrm{Fe}_{3} \mathrm{O}_{4} @ \mathrm{SiO}_{2} @ P V P A-C e(\mathrm{Iv})$ & $\mathrm{Ce}^{4+}$ & PVPA & $\begin{array}{l}\beta \text {-Casein/BSA } \\
(\text { molar ratio = } 1: 100)\end{array}$ & $500 \mathrm{fmol}$ & Nonfat milk & 9 & 104 \\
\hline $\mathrm{PI}-\mathrm{Fe}_{x} \mathrm{O}_{y}-\mathrm{ZrO}_{2}$ & $\mathrm{ZrO}_{2}$ & Polyimide & $\begin{array}{l}\beta \text {-Casein/BSA } \\
(\text { mass ratio }=1: 1000)\end{array}$ & - & Human serum & 4 & 106 \\
\hline DFMMOF & $\mathrm{Ti}^{4+} / \mathrm{Zr}-\mathrm{O}$ & PDA & $\begin{array}{l}\beta \text {-Casein/BSA } \\
(\text { molar ratio }=1: 1000)\end{array}$ & $5 \mathrm{fmol}$ & Nonfat milk & 15 & 109 \\
\hline MCTiMs & $\mathrm{TiO}_{2}$ & Cellulose & $\begin{array}{l}\beta \text {-Casein/BSA } \\
(\text { molar ratio }=1: 1000)\end{array}$ & $50 \mathrm{fmol}$ & Human serum & 4 & 110 \\
\hline PEG-Ce $/ \mathrm{CeO}_{2}-\mathrm{Fe}_{3} \mathrm{O}_{4}$ & $\mathrm{Ce}^{4+} / \mathrm{CeO}_{2}$ & PEG & $\begin{array}{l}\alpha-, \beta \text {-Casein/BSA } \\
(\text { mass ratios }=1: 200)\end{array}$ & $50 \mathrm{fmol}$ & Nonfat milk & 12 & 111 \\
\hline
\end{tabular}

one system is one of the most interesting topics in phosphoproteomics research. Jiang et al. prepared magnetic hydrazidefunctionalized PAMAM dendrimers embedded with $\mathrm{TiO}_{2}$ (denoted as TiHP-MNPs) for phosphopeptide enrichment (Fig. 11). ${ }^{114}$ The synergistic strength of multiple binding interactions (electrostatic attraction, hydrogen bonding, and Lewis acid-base interaction)

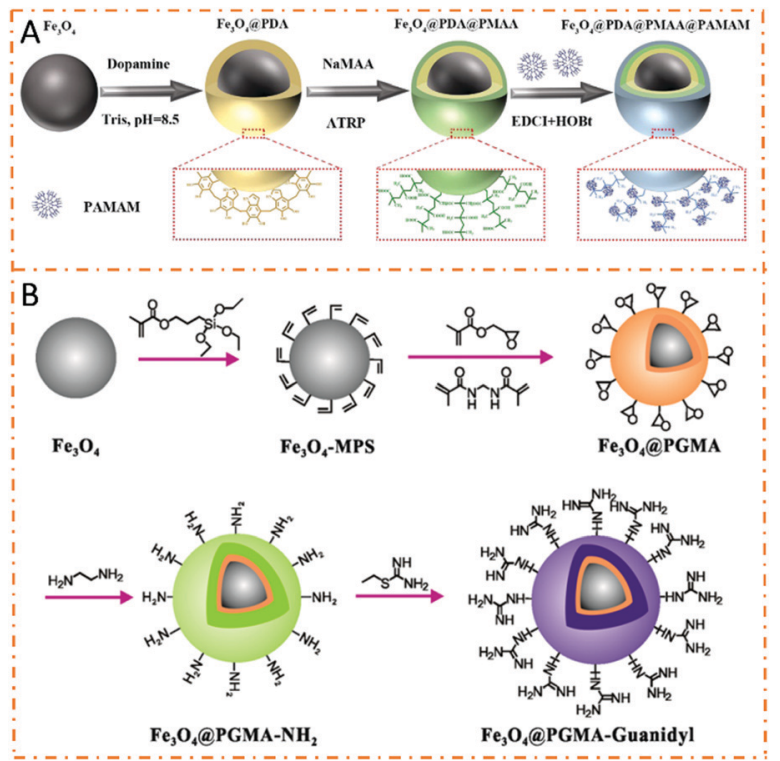

Fig. 10 Schematic illustration of the preparation and protein separation procedures of the amine-based magnetic polymer nanomaterials in phosphoproteomics. (A) $\mathrm{Fe}_{3} \mathrm{O}_{4}$ (aPDA@PMAA@PAMAM. Adapted from ref. 30 with permission from Copyright Royal Society of Chemistry. (B) $\mathrm{Fe}_{3} \mathrm{O}_{4} @ \mathrm{aPGMA}^{-}$ guanidyl. Reprinted with permission 113. contributed to an improved enrichment performance. The specificity toward phosphopeptides was as high as 1:500:500 (mass ratio of $\beta$-casein:BSA: ovalbumin), and the detection limit of $\beta$-casein digests was $0.4 \mathrm{fmol}$. Recently, our group coated polyvinyl pyrrolidone (PVP) and PEI on $\mathrm{Fe}_{3} \mathrm{O}_{4}$ nanoparticles to initiate the epitaxial growth of $\mathrm{Zn}-\mathrm{MOF}$ and the post-synthetic modification of arginine to prepare the SPIOs@PVP-PEI@MOF@Arg nanospheres (denoted as SPMA nanospheres). ${ }^{115}$ The integration of multiple affinity sites ( $\mathrm{Zn}-\mathrm{O}$ clusters, $\mathrm{NH}_{2}$, and guanidyl groups) into one material endowed SPMA nanospheres with a high enrichment performance with a low detection limit ( $\beta$-casein, $10 \mathrm{fmol}$ ) and high selectivity ( $\beta$-casein : BSA molar ratio $=1: 1000)$ toward global phosphopeptides. The nanospheres were further used to extract a tryptic digest of rat brain lysate. After enrichment, 1659 unique phosphopeptides (including mono- and multiphosphopeptides) were identified, indicating their good performance toward global

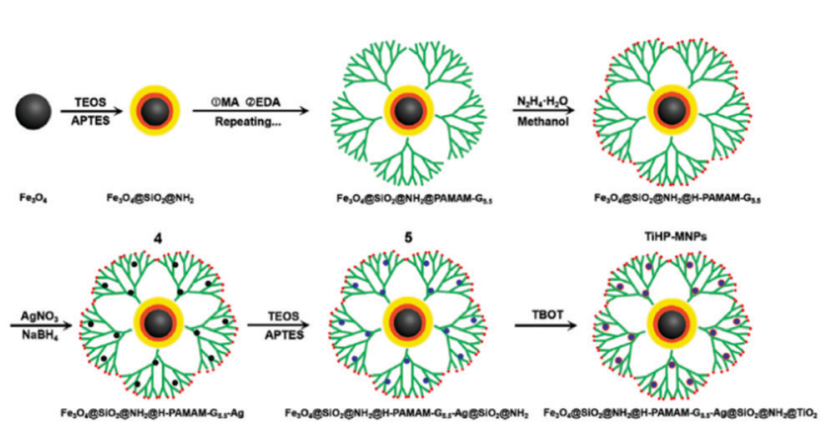

Fig. 11 Schematic illustration of the preparation of the magnetic polymer nanomaterials (TiHP-MNPs). Reprinted from ref. 114 with permission from Copyright Elsevier B.V. 
phosphopeptides. It can be seen that integrating multiple enrichment methods into a single affinity material will hopefully further improve the enrichment capacity for phosphopeptides.

\subsection{Molecularly imprinted magnetic polymer nanomaterials in phosphoproteomics}

Molecularly imprinted polymers (MIPs), as synthetic mimics of antibodies or enzymes, have found important applications in phosphopeptide enrichment. The introduction of MIPs favorably complements the deficiencies of affinity methods and remarkably increases the precise recognition of given phosphorylated amino acid residues (serine, threonine, and tyrosine phosphorylation). Chen et al. developed a dual-template docking-oriented molecular imprinting strategy to prepare molecularly imprinted mesoporous materials (MSNs). ${ }^{116}$ The resultant MSNs exhibited excellent selectivity, fast binding equilibrium, and large binding capacity toward phosphopeptides. Zhang et al. employed the epitope imprinting strategy to synthesize imprinted mesoporous materials (MIM) with structurally analogous phenylphosphonic acid (acted as the template) and mesoporous materials for the selective recognition of phosphorylated tyrosine. ${ }^{117}$ The MIM materials had excellent selectivity and a high adsorption capacity toward pTyr peptides from a mixture of angiotensin II peptide and $\beta$-casein (pY peptide: $\beta$-casein molar ratio $=1: 100$ ). However, more smart MIPs and MIPs combined with $\mathrm{Fe}_{3} \mathrm{O}_{4}$ are urgently needed to further improve enrichment efficiency.

\subsection{Smart magnetic polymer nanomaterials in phosphoproteomics}

Smart polymers can dynamically and reversibly change their structures and functions in response to external stimuli, such as temperature, $\mathrm{pH}$, electric field, and biomolecules. Smart polymers with unique tunability and controllability had a broad prospect in macromolecular separation and purification. Nishio et al. developed dual temperature- and pH-responsive chromatography based on a terpolymer composed of $\mathrm{N}$-isopropylacrylamide, $\mathrm{N}, \mathrm{N}$-dimethylaminopropylacrylamide, and butylmethacrylate to analyze phospho-amino acid, phosphopeptide, and oligonucleotides. ${ }^{118}$ Our group prepared $\mathrm{Fe}_{3} \mathrm{O}_{4} @ \mathrm{SiO}_{2} @ \operatorname{poly}(\mathrm{N}, \mathrm{N}$ dimethylamino-2-ethyl methacrylate-co-4-(3-(2-methacryloyloxy)ethyl)ureido)benzoic acid) composite microspheres through complementary multiple hydrogen-bonding interactions to selectively enrich phosphopeptides (dubbed SPMM) (Fig. 12). ${ }^{119}$ Driven by specific and tunable hydrogen bonding interactions, smart polymers display tunable adsorption behavior toward phosphorylated and non-modified peptides. The above-mentioned microspheres successfully captured cancer-related phosphopeptides from phosphoprotein Stathmin-1 and identified their relevant phosphorylation sites from the saliva and tissue lysate of oral carcinoma patients, demonstrating their potential toward phosphorylated disease marker detection and discovery. The combination of smart polymers with magnetic $\mathrm{Fe}_{3} \mathrm{O}_{4}$ can lead to the development of more intelligent enrichment materials for phosphoproteomics research in the near future.

\section{Magnetic polymer nanomaterials in multi-PTM proteomics}

Generally, a real bio-sample contains multiple PTM proteins. Both protein phosphorylation and glycosylation are closely related to physiological and pathological processes; therefore, it is necessary for proteomics studies to simultaneously obtain information about phosphoproteins and glycoproteins from one sample. Similar to single PTM, the sample pretreatment process for multi-PTMs is indispensable prior to MS analyses. Therefore, the design and preparation of multifunctional nanomaterials to achieve the simultaneous enrichment of phosphopeptides and glycopeptides is an attractive research topic. In recent years, some nanomaterials have been developed to simultaneously



Fig. 12 Schematic illustration of the preparation of the magnetic polymer nanomaterials (SPMM) and the general procedure for phosphopeptide extraction, digestion, enrichment, and identification. Adapted from ref. 119 with permission from Copyright Royal Society of Chemistry. 


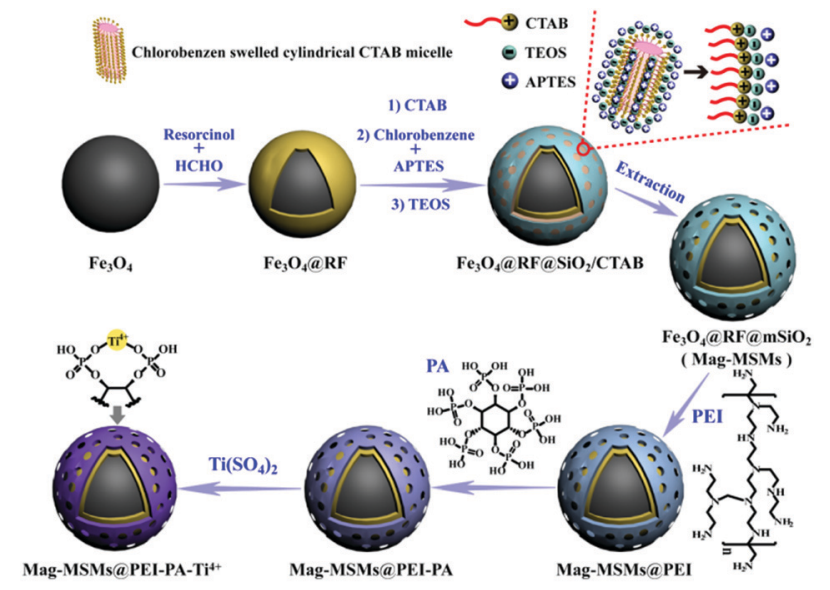

Fig. 13 Schematic illustration of the preparation of the IMAC-based magnetic polymer nanomaterials (MagG(aPEI@PA-Ti ${ }^{4+}$ ). Reprinted from ref. 123 with permission from Copyright Elsevier B.V.

capture phosphopeptides and glycopeptides. ${ }^{120-122}$ Among them, magnetic polymer nanomaterials manifest great advantages. For instance, Hong et al. designed and prepared a kind of microsphere modified with phytic acid (PA) and $\mathrm{Ti}^{4+}$ ions (denoted as MagMSMs@PEI-PA-Ti ${ }^{4+}$ ) (Fig. 13). ${ }^{123}$ According to the IMAC and HILIC mechanisms, the as-prepared Mag-MSMs@PEI-PA-Ti ${ }^{4+}$ microspheres were endowed with excellent properties for the enrichment of phosphopeptides and glycopeptides. For phosphopeptide enrichment, the prepared Mag-MSMs@PEI-PA-Ti ${ }^{4+}$ microspheres showed outstanding selectivity and high sensitivity in model proteins. After enrichment with the microspheres, a total of 1645 phosphopeptides from $200 \mu \mathrm{g}$ of HeLa cell extract were successfully detected. For glycopeptide enrichment, the MagMSMs@PEI-PA-Ti ${ }^{4+}$ microspheres also exhibited high selectivity and sensitivity. Meanwhile, $276 \mathrm{~N}$-glycopeptides corresponding to 132 glycoproteins were identified from $2 \mu \mathrm{L}$ of human serum after the enrichment process. Recently, they also reported another $\mathrm{Ti}^{4+}$ immobilized magnetic graphene nanocomposite (dubbed MagG@PEI@PA-Ti ${ }^{4+}$ ) to enrich both phosphopeptides and glycopeptides with outstanding performances. ${ }^{124}$ Although these affinity materials are endowed with the ability to enrich phosphopeptides and glycopeptides, they cannot achieve the simultaneous enrichment of phosphopeptides and glycopeptides from one buffer solution, leading to several problems including complicated operations, time consumption, and the loss of peptide information. Therefore, the design of magnetic polymer nanomaterials for the simultaneous enrichment of glycopeptides and phosphopeptides may be a key research topic for multi-PTM proteomics in the future.

\section{Conclusion and perspective}

In order to meet the requirements of MS-based proteomics, the purification of target proteins/peptides from complex samples is a crucial prerequisite. Among various affinity materials, magnetic polymer nanomaterials have made great progress in proteomics, especially PTM proteomics. Due to the advantages including mature preparation methods, fast magnetic response, and flexible functionality, magnetic polymer nanomaterials are widely used in the separation and enrichment of proteins/ peptides. In the above-discussed review, some most commonly used preparation methods of magnetic polymer nanomaterials are summarized. In ordinary proteomics, magnetic polymer nanomaterials produced by charge interactions and molecular imprinting are mostly used to capture ordinary proteins. In glycoproteomics applications, hydrophilic interaction-driven magnetic polymer nanomaterials manifest great potential in capturing glycoproteins/glycopeptides. It is worth noting that the exploitation of zwitterionic molecules with high hydrophilicity would be a hotspot in material design for glycopeptide enrichment in the future. In phosphoproteomics applications, IMAC/MOAC-based magnetic polymer nanomaterials are mainly used to enrich phosphopeptides. The design of high-performance chelating ligands is the key to ensure the phosphopeptide enrichment ability of IMAC/MOAC-based magnetic polymer nanomaterials. Therefore, magnetic polymer nanomaterials play an important role in sample pretreatment in proteomics.

However, there are still numerous challenges involved in designing high-efficiency magnetic polymer nanomaterials for comprehensive analyses of MS-based proteomics. First, the design of novel affinity molecules with high specificity toward target proteins/peptides is highly required. To search for highly specific affinity molecules, large-scale model calculations and molecular docking would be potential techniques. Second, there is currently a lack of multifunctional magnetic polymer nanomaterials to achieve the simultaneous enrichment of multiple PTM peptides. For example it is possible that a bifunctional magnetic polymer nanomaterial could simultaneously enrich glycopeptides and phosphopeptides from one sample. The design and preparation of multifunctional affinity materials will facilitate the comprehensive analysis of proteomics. Third, smart polymers have attracted increasing attention due to their excellent responses to external stimuli and meet the requirements of sample pretreatment in proteomics; thus, smart polymerbased magnetic nanomaterials hold huge potential in proteomics. This review summarizes the applications of magnetic polymer nanomaterials in proteomics and provides references for scientists interested in this field.

\section{Conflicts of interest}

There are no conflicts to declare.

\section{Acknowledgements}

This research was supported by the funds of the National Natural Science Foundation of China (No. 31771037), the National Key Research and Development Program of China (No. 2016YFC1100403), and Sichuan International Science and Technology Innovation Cooperation Project (No. 2019YFH0109). 


\section{References}

1 M. C. Wahl, C. L. Will and R. Luhrmann, Cell, 2009, 136, 701.

2 P. Van Damme, D. Gawron, W. Van Criekinge and G. Menschaert, Mol. Cell. Proteomics, 2014, 13, 1245.

3 E. Berezikov, G. Van Tetering, M. Verheul, J. van de Belt, E. Wienholds, R. H. Plasterk and E. Cuppen, Genome Res., 2016, 16, 1289.

4 M. Tyers and M. Mann, Nature, 2003, 422, 193.

5 R. E. Banks, M. J. Dunn, D. F. Hochstrasser, J. C. Sanchez, W. Blackstock, D. J. Pappin and P. J. Selby, Lancet, 2000, 356, 1749.

6 A. Bah and J. Forman-Kay, J. Biol. Chem., 2016, 291, 6696.

7 V. Csizmok and J. Forman-Kay, Curr. Opin. Struct. Biol., 2018, 48, 58.

8 M. Mann and O. N. Jensen, Nat. Biotechnol., 2003, 21, 255.

9 W. Gruber, T. Scheidt, F. Aberger and C. G. Huber, Cell Commun. Signaling, 2017, 15, 12.

10 E. Amit, R. Obena, Y. T. Wang, R. Zhuravel, A. J. F. Reyes, S. Elbaz, D. Rotem, D. Porath, A. Friedler, Y. J. Chen and S. Yitzchaik, Chem. Sci., 2015, 6, 4756.

11 E. L. Huttlin, M. P. Jedrychowski, J. E. Elias, T. Goswami, R. Rad, S. A. Beausoleil, J. Villen, W. Haas, M. E. Sowa and S. P. Gygi, Cell, 2010, 143, 1174.

12 M. B. Lazarus, Y. S. Nam, J. Y. Jiang, P. Sliz and S. Walker, Nature, 2011, 469, 564.

13 S. Vasaikar, Chen Huang and X. J. Wang, Cell, 2020, 177, 1035.

14 P. Dundr, K. Simon, K. Nemejcova, M. Bartu, I. Ticha, R. Michalkova, R. Jaksa, Z. Veckova and O. Kodet, Melanoma Res., 2019, 29, 157.

15 J. A. Shaw, D. S. Guttery, A. Hills, D. F. Garcia, K. Page, B. M. Rosales, K. S. Goddard, R. K. Hastings, J. L. Luo, O. Ogle, L. Woodley, S. Ali, J. Stebbing and R. C. Coombes, Clin. Cancer Res., 2017, 23, 88.

16 P. Bhatt, I. Vhora, S. Patil, J. Amrutiya, C. Bhattacharya, A. Misra and R. Mashru, J. Controlled Release, 2016, 226, 148.

17 S. Jeonga, M. J. Parka, W. Songa and H. S. Kim, Clin. Biochem., 2020, 78, 43.

18 J. B. Pan, Y. W. Hu and S. S. Sun, Nat. Commun., 2020, 11, 6139.

19 B. Cravatt, G. Simon and J. Yates, Nature, 2007, 450, 991.

20 X. Han, A. Aslanian and J. Yates, Curr. Opin. Chem. Biol., 2008, 12, 483.

21 V. Kolli, K. N. Schumacher and E. D. Dodds, Bioanalysis, 2015, 7, 113.

22 R. Pieper, C. L. Gatlin, A. J. Makusky, P. S. Russo, C. R. Schatz, S. S. Miller, Q. Su, A. M. McGrath, M. A. Estock and P. P. Parmar, Proteomics, 2003, 3, 1345.

23 J. Rush, A. Moritz, K. A. Lee, A. Guo, V. L. Goss, E. J. Spek, H. Zhang, X. M. Zha, R. D. Polakiewicz and M. J. Comb, Nat. Biotechnol., 2005, 23, 94.

24 M. K. Masud, J. Na, M. Younus, M. S. A. Hossain, Y. Bando, M. J. A. Shiddiky and Y. Yamauchi, Chem. Soc. Rev., 2019, 48, 5717.
25 C. Aydoğan, A. Gökaltun, A. Denizli and Z. E. Rassi, J. Sep. Sci., 2019, 42, 962.

26 G. Y. Qing, Q. Lu, X. L. Li, J. Liu, M. L. Ye, X. M. Liang and T. L. Sun, Nat. Commun., 2017, 8, 461.

27 Q. Yang, F. Lan, Z. Y. Liu, S. H. Ma, W. L. Li, Y. Wu and Z. W. Gu, J. Nanosci. Nanotechnol., 2015, 15, 1.

28 A. Masoudi, H. R. Madaah Hosseini, M. A. Shokrgozar, R. Ahmadi and M. A. Oghabian, Int. J. Pharm., 2012, 433, 129.

29 L. Q. Xie, F. Lan, W. L. Li, Z. Y. Liu, S. H. Ma, Q. Yang, Y. Wu and Z. W. Gu, Colloids Surf., B, 2014, 123, 413.

30 L. Z. Yu, B. Luo, Z. Y. Li, J. He, F. Lan and Y. Wu, J. Mater. Chem. B, 2020, 8, 1266.

31 B. Luo, X. Zhou, P. Jiang, Q. Yi, F. Lan and Y. Wu, J. Mater. Chem. B, 2018, 6, 3969.

32 F. Lan, K. X. Liu, W. Jiang, X. B. Zeng, Y. Wu and Z. W. Gu, Nanotechnology, 2011, 22, 225604.

33 F. Lan, S. H. Ma, Q. Yang, L. Q. Xie, Y. Wu and Z. W. Gu, Colloids Surf., B, 2014, 123, 213.

34 Q. Jia, Y. X. Peng, J. M. Pan, X. B. Huang, X. H. Niu and T. Zhang, New J. Chem., 2017, 41, 3308.

35 W. J. Yang, L. j. Liang, X. D. Wang, Y. P. Cao, W. Y. Xu, D. Q. Chang, Y. Gao and L. H. Wang, Biomater. Sci., 2019, 7, 247.

36 M. P. Calatayud, B. Sanza, V. Raffa, C. Riggio, M. R. Ibarra and G. F. Goya, Biomaterials, 2014, 35, 6389.

37 Q. Yang, Y. Wu, F. Lan, S. H. Ma, L. Q. Xie, B. He and Z. W. Gu, Nanotechnology, 2014, 25, 085702.

38 M. M. Zhang, J. Qiao and L. Qi, Anal. Chim. Acta, 2018, 1035, 70 .

39 A. Konwar, D. Chowdhury and A. Dan, Mater. Chem. Front., 2019, 3, 716.

40 J. P. Fan, J. X. Yua, X. M. Yang, X. H. Zhang, T. T. Yuan and H. L. Peng, Chem. Eng. J., 2018, 337, 722.

41 X. J. Li, B. L. Zhang, W. Li, X. F. Lei, X. L. Fan, L. Tian, H. P. Zhang and Q. Y. Zhang, Biosens. Bioelectron., 2014, 51, 261.

42 M. I. Shukoor, F. Natalio, M. N. Tahir, M. Divekar, N. Metz, H. A. Therese, P. Theato, V. Ksenofontov, H. C. Schröder, W. E. G. Muller and W. Tremel, J. Magn. Magn. Mater., 2008, 320, 2339.

43 L. Q. Xie, S. H. Ma, Q. Yang, F. Lan, Y. Wu and Z. W. Gu, RSC Adv., 2014, 4, 1055.

44 Q. Li, B. H. Wang, J. Q. Wang, X. J. Xi, Q. Chu, G. L. Dong and Y. Wei, New J. Chem., 2017, 41, 13673.

45 Q. Yang, Y. Zhu, M. G. Yang, S. H. Ma, Y. Wu, F. Lan and Z. W. Gu, Small, 2016, 12, 2344.

46 N. M. Riley, A. S. Hebert, M. S. Westphall and J. J. Coon, Nat. Chem., 2019, 1311, 5592.

47 M. Y. Chen, X. F. Shi, R. M. Duke, C. I. Ruse, N. Dai, C. H. Taron and J. C. Samuelson, Nat. Commun., 2017, 8, 15487.

48 P. Perego, L. Gatti and G. L. Beretta, Nat. Rev. Cancer, 2010, 10, 523.

49 K. Ohtsubo and J. D. Marth, Cell, 2006, 126, 855.

50 B. Luo, Q. Chen, J. He, Z. Y. Li, L. Z. Yu, F. Lan and Y. Wu, ACS Sustainable Chem. Eng., 2019, 7, 6043. 
51 M. Y. Wang, X. M. Zhang and C. H. Deng, Proteomics, 2015, 15, 2158.

52 Z. A. Lin, J. N. Zheng, F. Lin, L. Zhang, Z. Cai and G. N. Chen, J. Mater. Chem., 2011, 21, 518.

53 X. Zhang, X. He, L. Chen and Y. Zhang, J. Mater. Chem., 2012, 22, 16520.

54 Y. Zhang, W. Ma, D. Li, M. Yu, J. Guo and C. Wang, Small, 2014, 10, 1379.

55 Q. Yang, Y. Zhu, B. Luo, F. Lan, Y. Wu and Z. W. Gu, J. Mater. Chem. B, 2017, 5, 1236.

56 Z. Y. Li, B. Luo, L. Z. Yu, F. Lan and Y. Wu, J. Mater. Chem. $B, 2021,9,453$.

57 X. H. Zhang, J. W. Wang, X. W. He, L. X. Chen and Y. K. Zhang, ACS Appl. Mater. Interfaces, 2015, 7, 24576.

58 J. Su, X. W. He, L. X. Chen and Y. K. Zhang, Talanta, 2018, $180,54$.

59 H. P. Xiao, W. X. Chen, J. M. Smeekens and R. H. Wu, Nat. Commun., 2018, 9, 1692.

60 D. J. Li, Z. Y. Liu, R. M. Song, W. L. Yang, S. M. Zhai and W. H. Wang, RSC Adv., 2019, 9, 38038.

61 Q. Wu, B. Jiang, Y. J. Weng, J. X. Liu, S. W. Li, Y. C. Hu, K. G. Yang, Z. Liang, L. H. Zhang and Y. K. Zhang, Anal. Chem., 2018, 90, 2671.

62 J. h. Huang, H. Wan, Y. t. Yao, J. N. Li, K. Cheng, J. W. Mao, J. Chen, Y. Wang, H. Q. Qin, W. B. Zhang, M. L. Ye and H. F. Zou, Anal. Chem., 2015, 87, 10199.

63 S. S. Sun, P. Shah, S. T. Eshghi, W. M. Yang, N. Trikannad, S. Yang, L. J. Chen, P. Aiyetan, N. Höti, Z. Zhang, D. W. Chan and H. Zhang, Nat. Biotechnol., 2016, 34, 84.

64 H. Zhang, X. J. Li, D. B. Martin and R. Aebersold, Nat. Biotechnol., 2003, 21, 660.

65 G. Y. Qing, Q. Lu, Y. T. Xiong, L. Zhang, H. X. Wang, X. L. Li, X. M. Liang and T. L. Sun, Adv. Mater., 2017, 29, 1604670.

66 L. T. Liu, M. Yu, Y. Zhang, C. C. Wang and H. J. Lu, ACS Appl. Mater. Interfaces, 2014, 6, 7823.

67 Q. C. Cao, C. Ma, H. H. Bai, X. Y. Li, H. Yan, Y. Zhao, W. T. Ying and X. H. Qian, Analyst, 2014, 139, 603.

68 N. P. Dinh, T. Jonsson and K. Irgum, J. Chromatogr. A, 2011, 1218, 5880.

69 B. Luo, J. He, Z. Y. Li, F. Lan and Y. Wu, ACS Appl. Mater. Interfaces, 2019, 11, 47218.

70 Y. F. Ma, L. J. Wang, Y. L. Zhou and X. X. Zhang, Nanoscale, 2019, 11, 5526.

71 J. X. Wang, J. Li, Y. N. Wang, M. X. Gao, X. M. Zhang and P. Y. Yang, ACS Appl. Mater. Interfaces, 2016, 8, 27482.

72 J. X. Wang, J. Li, M. X. Gao and X. M. Zhang, Nanoscale, 2017, 9, 10750.

73 J. N. Li, J. Liu, Z. Y. Liu, Y. Tan, X. Y. Liu and F. J. Wang, Anal. Chem., 2017, 89, 4339.

74 N. R. Sun, H. Wu, H. M. Chen, X. Z. Shen and C. H. Deng, Chem. Commun., 2019, 55, 10359.

75 Y. N. Wang, J. X. Wang, M. X. Gao and X. M. Zhang, J. Mater. Chem. B, 2015, 3, 8711.

76 B. Jiang, Q. Wu, N. Deng, Y. B. Chen, L. H. Zhang, Z. Liang and Y. K. Zhang, Nanoscale, 2016, 8, 4894.
77 J. W. Wang, J. Z. Yao, N. R. Sun and C. H. Deng, J. Chromatogr. A, 2017, 1512, 1.

78 J. N. Li, F. J. Wang, J. Liu, Z. C. Xiong, G. Huang, H. Wan, Z. Y. Liu, K. Cheng and H. F. Zou, Chem. Commun., 2015, 51, 40936.

79 J. N. Li, F. J. Wang, H. Wan, J. Liu, Z. Y. Liu, K. Cheng and H. F. Zou, J. Chromatogr. A, 2015, 1425, 213.

80 C. F. Bi, Y. L. Liang, L. J. Shen, S. S. Tian, K. Zhang, Y. L. Li, X. W. He, L. X. Chen and Y. K. Zhang, ACS Omega, 2018, 3, 1572.

81 H. Wan, J. F. Huang, Z. S. Liu, J. N. Li, W. B. Zhang and H. F. Zou, Chem. Commun., 2019, 51, 9391.

82 Y. L. Wu, H. Z. Lin, Z. X. Xu, Y. Li, Z. B. Chen and C. H. Deng, Anal. Chim. Acta, 2020, 1096, 1.

83 R. Q. Wu, L. T. Li and C. H. Deng, Proteomics, 2016, 16, 1311.

84 Y. M. Zhao, Y. J. Chen, Z. C. Xiong, X. D. Sun, Q. Q. Zhang, Y. Y. Gan, L. Y. Zhang and W. B. Zhang, J. Chromatogr. A, 2017, 1482, 23.

85 Y. J. Chen, Z. C. Xiong, L. Y. Zhang, J. Y. Zhao, Q. Q. Zhang, L. Peng, W. B. Zhang, M. L. Ye and H. F. Zou, Nanoscale, 2015, 7, 3100.

86 Y. S. Ji, R. H. Lv, S. H. Song, J. F. Huang, L. W. Zhang, G. Huang, J. N. Li and J. J. Ou, Anal. Chim. Acta, 2019, 1053, 43.

87 J. F. Xie, G. Q. Zhong, C. Q. Cai, C. Y. Chen and X. M. Chen, Talanta, 2017, 169, 98.

88 X. Y. Sun, R. T. Ma, J. Chen and Y. P. Shi, J. Mater. Chem. B, 2018, 6, 688.

89 Y. Hao, R. X. Gao, D. C. Liu, G. Y. He, Y. H. Tang and Z. J. Guo, Talanta, 2016, 153, 211.

90 D. J. Li, Z. J. Bie, F. F. Wang and E. H. Guo, Analyst, 2018, 143, 4936.

91 M. Zhang, X. H. Zhang, X. W. He, L. X. Chen and Y. K. Zhang, Nanoscale, 2012, 4, 3141.

92 M. Hofweber and D. Dormann, J. Biol. Chem., 2019, 294, 7137.

93 K. Ashman and E. L. Villar, Clin. Transl. Oncol., 2009, 11, 356. 94 J. Zhang, M. J. Guy, H. S. Norman, Y. C. Chen, Q. Xu, X. Dong, H. Guner, S. Wang, T. Kohmoto, K. H. Young, R. L. Moss and Y. Ge, J. Proteome Res., 2011, 10, 4054.

95 Z. G. Wang, N. Lv, W. Z. Bi, J. L. Zhang and J. Z. Ni, ACS Appl. Mater. Interfaces, 2015, 7, 8377.

96 N. R. Sun, H. Wu, X. Z. Shen and C. H. Deng, Adv. Funct. Mater., 2019, 29, 1900253.

97 N. R. Sun, C. H. Deng, Y. Li and X. M. Zhang, ACS Appl. Mater. Interfaces, 2014, 6, 11799.

98 H. Z. Lin and C. H. Deng, Proteomics, 2016, 16, 2733.

99 J. B. Jiang, X. N. Sun, Y. Lia, C. H. Deng and G. L. Duan, Talanta, 2018, 178, 600.

100 J. B. Jiang, X. N. Sun, X. J. She, J. J. Li, Y. Li, C. H. Deng and G. L. Duan, Microchim. Acta, 2018, 185, 309.

101 L. Zhao, H. Q. Qin, Z. Y. Hu, Y. Zhang, R. A. Wu and H. F. Zou, Chem. Sci., 2012, 3, 2828.

102 Z. C. Xiong, L. Y. Zhang, C. L. Fang, Q. Q. Zhang, Y. S. Ji, Z. Zhang, W. B. Zhang and H. F. Zou, J. Mater. Chem. B, $2014,2,4473$. 
103 W. F. Ma, Y. Zhang, L. L. Li, Y. T. Zhang, M. Yu, J. Guo, H. J. Lu and C. C. Wang, Adv. Funct. Mater., 2013, 23, 107. 104 Z. G. Wang, G. Cheng, Y. L. Liu, J. L. Zhang, D. H. Sun and J. Z. Ni, J. Colloid Interface Sci., 2014, 417, 217.

105 Y. L. Liang, X. W. He, L. X. Chen and Y. K. Zhang, RSC Adv., 2014, 4, 18132.

106 X. M. Wang, Z. Y. Guo, Y. Zhang, M. L. Chen and J. H. Wang, Talanta, 2018, 188, 385.

107 M. Y. Wang, X. N. Sun, Y. Li and C. H. Deng, Proteomics, 2016, 16, 915.

108 Z. G. Wang, J. L. Zhang, D. H. Sun and J. Z. Ni, J. Mater. Chem. B, 2014, 2, 6886.

109 J. Q. Zhou, Y. L. Liang, X. W. He, L. X. Chen and Y. K. Zhang, ACS Sustainable Chem. Eng., 2017, 5, 11413.

110 J. J. Duan, X. M. He and L. N. Zhang, Chem. Commun., 2015, 51, 338.

111 X. Y. Long, Z. J. Zhang, J. Y. Li, D. Sheng and H. Z. Lian, Chem. Commun., 2017, 53, 4620.

112 C. T. Chen, L. Y. Wang and Y. P. Hou, Anal. Bioanal. Chem., 2011, 399, 2795.

113 Z. C. Xiong, Y. J. Chen, L. Y. Zhang, J. Ren, Q. Q. Zhang, M. L. Ye, W. B. Zhang and H. F. Zou, ACS Appl. Mater. Interfaces, 2014, 6, 22743.
114 D. D. Jiang, X. Q. Li, X. J. Lv and Q. Jia, Talanta, 2018, 185, 461.

115 B. Luo, M. G. Yang, P. P. Jiang, F. Lan and Y. Wu, Nanoscale, 2018, 10, 8391.

116 Y. Chen, D. J. Li, Z. J. Bie, X. P. He and Z. Liu, Anal. Chem., 2016, 88, 1447.

117 G. Y. Zhang, L. Y. Jiang, J. T. Zhou, L. H. Hu and S. H. Feng, Chem. Commun., 2019, 55, 9927.

118 T. Nishio, E. Ayano, Y. Suzuki, H. Kanazawa and T. Okano, J. Chromatogr. A, 2011, 1218, 2079.

119 B. Luo, L. Z. Yu, Z. Y. Li, J. He, C. J. Li, F. Lan and Y. Wu, J. Mater. Chem. B, 2020, 8, 8414.

120 H. J. Zheng, J. X. Jia, Z. Li and Q. Jia, Anal. Chem., 2020, 92, 2680.

121 Q. Lu, C. Chen, Y. T. Xiong, G. D. Li, X. F. Zhang, Y. H. Zhang, D. D. Wang, Z. C. Zhu, X. L. Li, G. Y. Qing, T. L. Sun and X. M. Liang, Anal. Chem., 2020, 92, 6269.

122 N. R. Sun, H. Wu and X. Z. Shen, Microchim. Acta, 2020, 187, 195.

123 Y. Y. Hong, Q. L. Zhan, Y. Zheng, C. L. Pu, H. L. Zhao and M. B. Lan, Talanta, 2019, 197, 77.

124 Y. Y. Hong, H. L. Zhao, C. L. Pu, Q. L. Zhan, Q. Y. Sheng and M. B. Lan, Anal. Chem., 2018, 90, 11008. 